\title{
SEDIMENTOLOGY
}

\section{Dynamics of settling-driven convection beneath a sediment- laden buoyant overflow: implications for the length-scale of deposition in lakes and the coastal ocean}

\begin{tabular}{|c|c|}
\hline Journal: & Sedimentology \\
\hline Manuscript ID & SED-2018-OM-085.R1 \\
\hline Manuscript Type: & Original Manuscript \\
\hline $\begin{array}{r}\text { Date Submitted by the } \\
\text { Author: }\end{array}$ & $n / a$ \\
\hline Complete List of Authors: & $\begin{array}{l}\text { Davarpanah Jazi, Shahrzad; University of Toronto, Physical and } \\
\text { Environmental Sciences } \\
\text { Wells, Mathew; University of Toronto, Physical and Environmental } \\
\text { Sciences }\end{array}$ \\
\hline Keywords: & $\begin{array}{l}\text { Sediment-laden gravity current, Settling-driven convection, Turbidity } \\
\text { currents, Density ratio, Stokes settling velocity, Overflow }\end{array}$ \\
\hline \multicolumn{2}{|c|}{$\begin{array}{l}\text { Note: The following files were submitted by the author for peer review, but cannot be converted to PDF } \\
\text { You must view these files (e.g. movies) online. }\end{array}$} \\
\hline $\begin{array}{l}\text { MovieS1.wmv } \\
\text { MovieS2.wmv } \\
\text { MovieS3.wmv } \\
\text { MovieS4.wmv } \\
\text { MovieS5.wmv } \\
\text { MovieS6.wmv }\end{array}$ & \\
\hline
\end{tabular}




\title{
Dynamics of settling-driven convection beneath a sediment-laden buoyant overflow: implications for the length-scale of deposition in lakes and the coastal ocean
}

\author{
Shahrzad Davarpanah Jazi and Mathew G. Wells \\ Department of Physical \& Environmental Sciences, University of Toronto \\ 1065 Military Trail, M1C 1A4, Toronto, ON, Canada \\ Email: sh.davarpanahjazi@mail.utoronto.ca, Email: wells@utsc.utoronto.ca
}

ABSTRACT

A series of laboratory experiments were conducted in order to determine how settling-driven convection influences the length-scale over which the majority of particles settle beneath a buoyant sediment-laden plume spreading over a denser saline layer. This system is analogous to sediment-laden river water spreading into a lake or the coastal ocean. The key dimensionless parameter that controls the settling dynamics of such flows is the density ratio, defined as the ratio of density differences due to the added salt and sediment. For a buoyant plume, this ratio has to be greater than unity, so that the experiments in the current study were performed for density ratios between one and five. When density ratio was close to one, settling-driven convection was vigorous and the length-scale over which sedimentation occurred was very small. A strong secondary turbidity current was generated in this case. On the other hand, for larger values of density ratio, the predicted length-scale over which a secondary plume was generated increased proportional with the density ratio. A complete mathematical expression for this length-scale was developed using recent theory that described the time-scale over which settling-driven convection evolved. The theoretically predicted propagation length-scale showed very good quantitative agreement with laboratory experiments. The use of the dimensionless density ratio allows the expression to predict which sediment-laden river plumes in lakes and the coastal ocean could quickly form secondary turbidity currents.

Keywords: Sediment-laden gravity current, settling-driven convection, turbidity currents, density ratio, Stokes settling velocity, overflow. 


\section{INTRODUCTION}

Rivers are the main pathways by which sediment is transported to the coastal regions of lakes and the ocean (Mulder \& Syvitski, 1995). In a lake, a sediment-laden river is often denser than the receiving waters and so can readily plunge and form a turbidity current, as originally observed in pioneering work by Forel (1885) in Lake Geneva. In contrast, when a river flows into the coastal ocean, the buoyant density difference between the fresh and saline water is usually far greater than the unstable density difference due to the suspended sediment load. Hence, almost all sediment-laden rivers will form surface plumes in the coastal ocean (Mulder \& Syvitski, 1995). The processes that control the length-scale over which sediment deposits

11 beneath these buoyant sediment-laden plumes is thus a key geological question. This lengthscale of deposition is directly related to the length-scale that the buoyant plume propagates

13 before losing all its sediment from beneath. Such length-scale has been described as the product

14 of the horizontal velocity of the buoyant plume and a time-scale over which sediment is lost

15 (Geyer et al., 2004; Hill et al., 2000). The horizontal velocity of a surface plume is well 16 understood (Yuan \& Horner-Devine, 2017), and in the absence of strong winds or tides, it is 17 largely determined by buoyancy forces (Horner-Devine et al., 2015). The time-scale over which 18 sedimentation occurs has been the focus of recent work by Hoyal et al. (1999b), Burns \& 19 Meiburg (2012, 2015) and Davarpanah Jazi \& Wells (2016), who identified settling-driven 20 convection as the potentially dominant fluid dynamical process that can rapidly transport 21 sediment from beneath sediment-laden buoyant plumes. Previous experiments (Maxworthy, 22 1999; Parsons et al., 2001; Snow \& Sutherland, 2014; Sutherland et al., 2018) and direct 23 observations of buoyant surface sediment-laden plumes (Hughes Clarke et al., 2014; Hizzett et $24 a l ., 2017)$ showed that under certain conditions, the rapid sediment loss beneath such plumes can 25 generate a secondary turbidity current, which could provide an important mechanism to transport 26 sediment to the depths of the ocean from the continental margin. For instance, direct field 27 monitoring by Clare et al. (2016) has revealed that 70\% of observations of the triggering of 28 secondary turbidity currents were linked to the sediment-laden plume in Howe Sound near the 29 Squamish River in BC, Canada. Since sediment-laden gravity currents are one of the main 30 mechanisms for transporting sediments into the deep ocean, where deep sand layers can form 31 (Meiburg \& Kneller, 2010), this study aims to use laboratory experiments to quantify the 
1 conditions that can enhance sedimentation beneath such buoyant river plumes. Particularly, this

2 study identifies the specific conditions that could potentially result in the formation of secondary

3 turbidity currents from the many rivers in the coastal ocean that usually have low sediment loads

4 and would almost always form surface plumes rather than plunging underflows (Mulder \&

5 Syvitski, 1995).

The length-scale over which a surface plume propagates and loses sediment will give a firstorder estimate of the distribution of sediment deposition from a river mouth, as illustrated schematically in Figure 1. If there are no currents beneath the surface plume, then the distance at which all of the sediment has fallen out of the plume determines the zone of deposition. If the concentrations are high enough, this depositing sediment could also potentially form a secondary turbidity current. Intuitively, the extent of propagation over which sediment is lost $\left(L_{\text {prop }}\right)$ can be 13 approximated as follows:

$$
L_{\text {prop }}=U T_{s}=U\left(\bar{H} / w_{S}\right)
$$

where $U$ is the horizontal velocity of the buoyant plume and $T_{S}$ is the time-scale over which particles settle through the moving surface plume. If particles are only being lost by a slow settling rate over the mean thickness of the plume $(\bar{H})$, then the settling time-scale is simply determined as $T_{S}=\bar{H} / w_{S}$, where $w_{S}$ is the Stokes settling velocity of the sediment particles (Geyer et al., 2004; Hill et al., 2000). The horizontal velocity of a buoyant plume $(U)$ is a function of the reduced gravity $\left(g^{\prime}\right)$ between the plume and ambient and the thickness at the 23 plume head $(H)$. Thus, this velocity is given by $U=\operatorname{Fr}\left(g^{\prime} H\right)^{1 / 2}$, where the reduced gravity is defined as $g^{\prime}=g \Delta \rho / \rho$, with $g$ the gravitational acceleration $\left(9.81 \mathrm{~m} \mathrm{~s}^{-2}\right)$ and $\Delta \rho$ and $\rho$ are respectively the density difference and average density between the current and the saline ambient with units of $\mathrm{kg} \mathrm{m}^{-3}$. The Froude number is the key dimensionless parameter for describing gravity current dynamics and is defined as $\mathrm{Fr}=U /\left(g^{\prime} H\right)^{1 / 2}$. Essentially the Froude number compares the observed speed to that of an internal wave speed. Numerous experimental 29 studies have consistently found the Froude number to be order one (i.e. Turner, 1979; Simpson, 30 1982; Gladstone \& Pritchard, 2010; Snow \& Sutherland, 2014), which is close to the value of 1 / $31 \sqrt{2}$ found in theoretical studies (Benjamin, 1968; Huppert, 2006; Meiburg \& Kneller, 2010). 
1 Recent direct numerical simulations of buoyant double-diffusive gravity currents by Penney \&

2 Stastna (2016) have suggested that a no-slip condition (representing a solid lid) may increase 3 drag compared to a free-slip condition (representing an air-water interface), and hence they 4 would predict different Fr than for buoyant plumes compared to regular bottom gravity currents.

Using typical values for laboratory and field situations, Equation (1) predicts very large propagation length-scales if the only settling process considered is Stokes settling velocity. For 8 instance a typical gravity current in a laboratory experiment with a strong buoyancy difference, has a speed of order $U \sim 0.1 \mathrm{~m} \mathrm{~s}^{-1}$. The mean thickness of a typical laboratory gravity current is of order $\bar{H}=0.1 \mathrm{~m}$. Hence, using for example Silicon Carbide (SiC) sediment particles of size $117.8 \times 10^{-6} \mathrm{~m}$ with Stokes settling velocity of $w_{S}=7.7 \times 10^{-5} \mathrm{~m} \mathrm{~s}^{-1}$, implies a settling time of $T_{S}=$ $121300 \mathrm{~s}$. Therefore, assuming that the current is moving at $0.1 \mathrm{~m} \mathrm{~s}^{-1}$, it would need to propagate 13 the very large distance of $130 \mathrm{~m}$ for all the particles to settle out of the plume, and hence 14 laboratory plumes with fine sediment might be predicted to propagate to the end of any realistic 15 experimental tank before losing all of their sediment. In contrast, previous laboratory 16 experiments have found that settling-driven convection is much more important than just the 17 Stokes settling velocity, so that laboratory plumes with fine sediment particles can lose sediment 18 at much faster rates (Maxworthy, 1999; Parsons et al., 2001; Snow \& Sutherland, 2014, 19 Sutherland et al., 2018). The scaling in Equation (1) assumes that particles are settling in a 20 laminar manner within the gravity current. If the flow is turbulent however, so that the 21 concentration is well mixed, then the average mass concentration ( $C$ with units of $\left.\mathrm{kg} \mathrm{m}^{-3}\right)$ in the 22 flow changes with time as $C(t)=C_{o} e^{\left(-t W_{s} / \bar{H}\right)}$ (Martin \& Nokes, 1988; Sparks et al., 1991), 23 where $C_{0}$ is the initial mass concentration of the flow $\left(\mathrm{kg} \mathrm{m}^{-3}\right)$. With such an exponential decay, $2495 \%$ of particles settle out after three settling time-scales, i.e. an even greater distance is implied 25 by Equation (1).

There are a number of mechanisms by which the time-scale used in Equation (1) could be much smaller than that predicted from the Stokes settling velocity of a single particle, including 29 flocculation (Rouhnia \& Strom, 2015, 2017) and settling-driven convection (Burns \& Meiburg, 30 2012, 2015). This study will focus on the potential role of settling-driven convection, as the 31 description of increased settling rates due to flocculation is now quite mature (Rouhnia \& Strom, 

2015, 2017). Several field observations have found that sediment is lost from a buoyant plume at 2 rates much faster than predicted by the Stokes settling velocity. For instance, Nowacki et al. (2012) computed the sediment removal rate from the Colombia River, USA and determined that the settling rate $\left(10 \mathrm{~mm} \mathrm{~s}^{-1}\right)$ was substantially larger than the settling velocity of a single particle $5 \quad\left(2 \mathrm{~mm} \mathrm{~s}^{-1}\right)$. Similarly, Scheu et al. (2015) used acoustic backscatter measurements beneath a river plume in a thermally stratified lake, to infer increases of an order of magnitude over the Stokes settling velocities of the suspended sediments settling from turbid river plumes. In the absence of flocculation, the most likely potential mechanism for these increased sedimentation rates is settling-driven convection, the vigour of which depends on the unstable sediment contrast between the layers.

Settling-driven convection is an important instability that can occur when a layer of fresh sediment-laden water lies above a layer of saline water (Fig. 2). Initially this configuration can

14 be stable if the mean density of the upper layer is less than that of the lower layer (as shown in 15 Figure 2A). However, as sediment settles through the saline interface, a layer of particle rich fluid forms that contains both salt and sediment, and is now denser than the fluid below (the nose

17 region in Figure 2B). Since this layer is unstable, convection of sediment-laden plumes begins

18 (Fig. 2C). These dense sediment-laden finger-like plumes sink with vertical velocities that are 10 to 100 times larger than Stokes settling velocity (Hoyal et al., 1999b; Burns \& Meiburg, 2012, 2015; Davarpanah Jazi \& Wells, 2016). This process is highly important to Equation (1), as it suggests that a much shorter time-scale $T_{s}$ is relevant for sediment-laden buoyant plumes, so that the deposition length-scale will be far less than predicted by only assuming Stokes settling velocity of a single particle. Such finger-like plumes have been seen in a number of studies

24 (Bradly, 1965; Hoyal et al., 1999b) and this process is seen to greatly increase the particle removal rate from an otherwise buoyant upper layer (Houk \& Green, 1973; Green, 1987; Chen, 1997; Hoyal et al., 1999a, b; Maxworthy, 1999; Parsons \& Garcia, 2000; Parsons et al., 2001;

27 Davarpanah Jazi \& Wells, 2016). Recent work by Davarpanah Jazi \& Wells (2016) showed that in a salt/sediment configuration with no horizontal velocities, the vigour of convection was dictated by density ratio defined as $R_{\rho}=\Delta \rho_{S} / \Delta \rho_{C}$, the ratio of density differences due to the 30 added salt $\left(\Delta \rho_{S}\right)$ and sediment $\left(\Delta \rho_{C}\right)$. For a sediment-laden layer of fresh water to float above a 31 saline layer, $R_{\rho}$ must be greater than one. The most vigorous convection was found to occur for 
marginal stability when $R_{\rho}$ was very close to one. Theoretical and numerical studies of settlingdriven convection (Burns \& Meiburg, 2012, 2015; Yu et al., 2013, 2014; Shao et al., 2017) have quantified the time-scales for these processes, and revealed the internal dynamics of the velocity fields that are difficult to see experimentally.

One of the key findings of the previous experiments and field observations on buoyant sediment-laden plumes is that settling-driven convection is an important mechanism for moving sediments rapidly from surface plumes to the lake or ocean bed, where dense secondary turbidity currents can potentially form (Maxworthy, 1999; Parsons et al., 2001; Snow \& Sutherland, 2014; Hughes Clarke et al., 2014; Sutherland et al., 2018). As almost all sediment-laden river plumes are initially buoyant, many papers have cited Parsons et al. (2001) to suggest settling-driven convection could be a key process by which turbidity currents can be formed in the coastal ocean near river mouths, which ultimately transport sediment to deep regions of the ocean (Meiburg \&

14 Kneller, 2010). It is very challenging in a field study to isolate the specific mechanism by which secondary turbidity currents can be generated from a buoyant sediment-laden plume (Gales et al., 2018), and only a limited number of field studies have attempted to investigate this process (see

17 for example optical backscatter measurements of Hughes Clarke et al. 2014, Kineke et al. 2000 18 and Hill et al. 2008). This has placed great importance to these earlier experiments, especially 19 Parsons et al. (2001). In the current study, the aim is to revisit these earlier experiments, and 20 improve the understanding on processes that set the length-scale in Equation (1) in light of the 21 recent improvements to the theoretical understanding of the time-scales of settling-driven 22 convection (Burns \& Meiburg, 2012, 2015; Yu et al., 2013, 2014; Shao et al., 2017). 23 Specifically, this paper aims to extend the initial study of Maxworthy (1999) by applying the 24 time-scale used in Burns \& Meiburg $(2012,2015)$ to determine how the length-scale in Equation 25 (1) varies as a function of density ratio $\left(R_{\rho}\right)$.

The experiments in this paper aim to quantify how settling-driven convection could control the length-scale of deposition beneath a buoyant plume, and isolate the specific conditions under which secondary turbidity currents can form. As this process is challenging to study in the field, the presented experimental visualizations of such processes will help geologists to better conceptualize field observations. Using the most recent results from modelling of settling-driven 
1 convection, a new equation is developed to describe the distance over which sediment is lost due

2 to settling-driven convection. There is excellent agreement between the quantitative theory and

3 the laboratory results. The paper ends with an extrapolation of the findings of this study to

4 predict the relevant length-scales for river plumes entering the coastal ocean.

EXPERIMENTAL DESIGN

In order to better understand how the process of settling-driven convection controls deposition beneath buoyant plumes in lakes and the coastal ocean, a series of experiments were performed, where a controlled volume of sediment-laden fluid was released into a large tank that contained a well-mixed saline solution (Fig. 3). The large tank had dimensions of $1.83 \times 0.55 \times 0.305 \mathrm{~m}$, and sediment-laden fluid was initially contained behind a removable metal barrier in a compartment of dimensions $0.35 \times 0.115 \times 0.23 \mathrm{~m}$. The two compartments were the same temperature, as they

14 were both filled with tap water stored in large vessels that had equilibrated with room temperature $\left(18.5 \pm 2.3{ }^{\circ} \mathrm{C}\right)$. Keeping the temperature constant throughout all experiments, resulted in a two-component salt/sediment configuration similar to experiments of Maxworthy (1999). The ambient saline solution was prepared from high purity food grade salt. The sediment used in the experiments was Silicon Carbide ( $\mathrm{SiC}$ ) grinding powder with a density of $\rho_{S i C}=3210$ $\mathrm{kg} \mathrm{m}^{-3}$. This material is monodispersed and non-cohesive and was previously used in the experiments of Maxworthy (1999), Hoyal et al. (1999b), Davarpanah Jazi \& Wells (2016) and Sutherland et al. 2018. The median diameter of particles was $7.8 \times 10^{-6} \mathrm{~m}$, resulting in a predicted Stokes settling velocity of $7.7 \times 10^{-5} \mathrm{~m} \mathrm{~s}^{-1}$.

In these experiments, the salinity contrast between the surface plume and the ambient fluid was kept constant, and the sediment concentration was increased. Thus, the density ratios varied from $R_{\rho}=\infty$ (no sediment) to $R_{\rho}=1$ (neutral stability). The cases where $R_{\rho}<1$ would have the

27 sediment being denser than the ambient fluid so would immediately form underflows. The density of the saline ambient $\left(\rho_{S}\right)$ was kept constant at $1002.5 \pm 0.4 \mathrm{~kg} / \mathrm{m}^{3}$, while the amount of sediment added to surface plume was varied. The different densities of sediment-laden water $\left(\rho_{C}\right)$ 30 were obtained by adding various masses of sediment $\left(0 \leq m_{C} \leq 0.065 \mathrm{~kg}\right)$ to the fixed volume of

31 fresh water within the small compartment. The mass of sediment was determined using an Ohaus 
1 SPX222 balance (Ohaus Corporation, Parsippany, NJ, USA) with precision of $10^{-2} \mathrm{~g}$. The 2 densities of saline water $\left(\rho_{S}\right)$ and the water in the compartment, before adding sediment $\left(\rho_{\text {comp }}\right)$, were measured using an Anton Paar DMA 35 Ex portable densitometer (Anton Paar USA Inc., Ashland, VA, USA) with an accuracy of $\pm 10^{-3} \mathrm{~g} \mathrm{~cm}^{-3}$ and a resolution to $10^{-4} \mathrm{~g} \mathrm{~cm}^{-3}$. The temperatures $\left(t_{S}\right.$ and $t_{\text {comp }}$ ) were measured simultaneously with the same instrument to the precision of $0.2^{\circ} \mathrm{C}$.

The density of a fluid can be determined as $\rho_{f}=\rho_{0}+\Delta \rho_{S}+\Delta \rho_{C}$ and is linearly related to both concentrations of salt and sediment. Here, $\rho_{0}$ is the density of clear fresh water at $20^{\circ} \mathrm{C}(998.2 \mathrm{~kg}$ $\mathrm{m}^{-3}$ ). The added density due to the added salt was calculated using $\Delta \rho_{S}=\rho_{S}-\rho_{\text {comp }}$, where the

11 density of fresh water in the compartment is $\rho_{\text {comp }}=999.1 \pm 0.2 \mathrm{~kg} \mathrm{~m}^{-3}$. The density anomaly due to the added sediment was calculated as $\Delta \rho_{C}=\gamma C \rho_{\text {comp }}$, in which $\gamma$ is the density expansion 13 coefficient for $\mathrm{SiC}$ particles defined as $\left(\rho_{S i C}-\rho_{c o m p}\right) / \rho_{S i C}$. Furthermore, $\varphi$ is the mass 14 concentration of sediment particles $\left(\mathrm{kg} \mathrm{kg}^{-1}\right)$ denoted by $\varphi=m_{C} /\left(m_{C}+m_{\text {comp }}\right)$, where the mass

15 of the water in the small compartment $\left(m_{\text {comp }}\right)$ was determined as $m_{\text {comp }}=\rho_{\text {comp }} V_{\text {comp }}$, in which $V_{\text {comp }}$ was the volume of the compartment $\left(\mathrm{m}^{3}\right)$.

The entire tank was initially filled with saline water with density $\rho_{S}$, and then the barrier was inserted to isolate the smaller compartment. With the use of two small pumps, the saline water in this compartment was replaced with freshwater, by discharging salt water out and pumping fresh water in simultaneously. An equivalent of four times the volume of the small compartment was replaced in order to guarantee that $99 \%$ of the saline water was flushed out (Zhixin et al., 2014). An electrical mixer was used to keep the fluid well-mixed while being replaced.

The sediment particles were then added to the fresh water in the small compartment and a well-mixed constant volume of sediment-laden water was prepared. The electrical mixer kept the

27 fluid stirred to inhibit the settling of particles and the total time between addition of sediment and removal of barrier was kept to less than two minutes. Each experiment commenced with the gentle removal of the metal barrier $10 \mathrm{~s}$ after the mixer was turned off to prevent turbulent

30 motion it produced within the fluid. In addition, food dye was added to the sediment water to 31 further improve flow detection. Digital cameras were used to capture the behaviour of the flow 
1 from different angles through photos and movies. Two large LED light panels provided bright 2 and uniform lighting at the background in order to produce clear, sharp photos and movies from 3 the sediment-laden gravity current in motion.

A total of 19 experiments with density ratios in the range of $0.687 \leq R_{\rho} \leq \infty$ were performed. Full details of all 19 experiments, including $R_{\rho}, m_{C}, L_{p r o p}$ and the behaviour of sediment-laden overflows, are summarized in Table 1. The six supplemental movies are available online and are representative of the major trends in the behaviour of the current. In this table the experiments are in an ascending order based on their density ratio. The experiment with $R_{\rho}=\infty$ (Movie $\mathrm{S} 6$ in the Supplemental section) had no sediment, and the one experiment with $R_{\rho}=0.687$ (Movie S1

11 in the Supplemental section) had sediment load such that it was initially denser than saline ambient; all the other 17 experiments were initially positively buoyant and were in the range $1.021 \leq R_{\rho} \leq 4.575$. The above two experiments $\left(R_{\rho}=\infty\right.$ and 0.687$)$ were performed only for

14 comparison purposes, as the main focus of this study was on sediment-laden overflows. The 15 propagation length-scale of the gravity current $\left(L_{p r o p}\right)$ was measured by visually determining the distance at which the thickness of the gravity current became less than $0.01 \mathrm{~m}$ and had essentially stopped. The error bars in the determinations of $L_{\text {prop }}$ represent an estimate of the distance over which the gravity current changes from $0.02 \mathrm{~m}$ to $0 \mathrm{~m}$ thickness.

\section{THEORY}

Settling-driven convection can lead to far greater loss of sediments than Stokes settling, so that use of Equation (1) would predict a much smaller and more realistic deposition length-scale.

24 In this section, the scaling of $L_{\text {prop }}$ is now modified to take into account theoretical scaling of the sedimentation time-scale, introduced by Burns \& Meiburg $(2012,2015)$ to show how the density ratio $\left(R_{\rho}\right)$ and the stratification influence the propagation length-scale. In order to use Equation (1) a horizontal velocity $(U)$ and a sedimentation time-scale $\left(T_{S}\right)$ are needed. For the former, the horizontal velocity of the plume is a function of the reduced gravity, which can be expressed in terms of the contribution of sediment and salt density anomalies as,

$$
U=\operatorname{Fr}\left(\frac{g H}{\rho}\left(-\Delta \rho_{C}+\Delta \rho_{S}\right)\right)^{1 / 2}
$$


2 where $\Delta \rho_{S}$ and $\Delta \rho_{C}$ are the added density due to the added salt and mass fraction of sediment 3 respectively. By introducing the definition of density ratio $\left(R_{\rho}=\Delta \rho_{S} / \Delta \rho_{C}\right)$ previously used by 4 Davarpanah Jazi \& Wells (2016), this velocity can be rewritten in terms of density ratio $\left(R_{\rho}\right)$ and 5 Froude number (Fr) as,

$$
U=\operatorname{Fr}\left(\frac{g \Delta \rho_{S}}{\rho} H\left(1-\frac{1}{R_{\rho}}\right)\right)^{1 / 2}
$$

The sedimentation time-scale $\left(T_{S}\right)$ is determined by the dynamics of the instability at the 11 settling of sediment particles from the fresher layer into the denser saline layer (Fig. 2A) drives 12 the settling-driven convection instability. A very thin layer of fluid, just below the interface 13 containing both salt and sediment, forms a "nose" of unstable stratification with length-scale $14\left(L_{C}\right)$, as shown in Figure 2B. The convective instability at the base of the sediment-laden fluid is 15 controlled by this thin "nose" region, as there is an unstable density inversion due to accumulation of settling sediment from above (Burns \& Meiburg, 2012). When this layer grows 17 sufficiently large, the dense material will sink as a convective plume (Fig. 2C). The numerical 18 simulations of Burns \& Meiburg $(2012,2015)$ and Shao et al. (2017) have shown that within the 19 thin nose region of thickness $L_{C}$, the fluid dynamics are dominated by viscosity. This implies that 20 both Grashof number and Reynolds number are equal to one at the point just before instability 21 occurs.

23 The Grashof number is defined as,

$$
\mathrm{Gr}=\frac{g_{C}^{\prime} L_{C}^{3}}{v^{2}}
$$

where $g_{C}^{\prime}=g \Delta \rho_{C} / \rho_{0}$ is the reduced gravity defined in terms of the density difference due to the added sediment $\left(\Delta \rho_{C}\right)$ and density of fresh water $\left(\rho_{0}\right)$ (Burns $\&$ Meiburg, 2012, 2015) and $v=10^{-}$

$29{ }^{6} \mathrm{~m}^{2} \mathrm{~s}^{-1}$ is the coefficient of kinematic viscosity of fresh water at $20{ }^{\circ} \mathrm{C}$. In this region, a Reynolds number can also be defined as, 


$$
\operatorname{Re}=\frac{w_{S} L_{C}}{v}
$$

4 where the vertical velocity of fluid in this layer is assumed to be the same as the settling velocity $5 \quad w_{s}$ (Shao et al., 2017).

7 The important time-scale for convective instability can be derived through the following steps.

8 First, assuming $\mathrm{Re}=1$ implies that

$$
L_{C}=\frac{v}{w_{S}}
$$

11

12 Similarly assuming that in the viscosity dominated unstable nose region $\mathrm{Gr}=1$ results in a 13 scaling for the thickness of the nose region in terms of the viscosity and reduced gravity as,

$$
L_{C}=\left(\frac{v^{2}}{g_{C}^{\prime}}\right)^{1 / 3}
$$

17 Note that $g_{C}^{\prime}$ is the reduced gravity defined in terms of the density difference due to the added 18 sediment $\left(\Delta \rho_{C}\right)$ and density of fresh water $\left(\rho_{0}\right)$. By equating Equations (6) and (7), the settling 19 velocity within the convectively unstable nose region is shown to be related to the reduced 20 gravity of the sediment layer and viscosity as,

$$
w_{S}=\left(g_{C}^{\prime} v\right)^{1 / 3}
$$

24 Therefore using Equation (6), the time-scale $\left(T_{C}=L_{C} / w_{s}\right)$ for a particle of velocity $w_{S}$ to fall 25 into the unstable nose region of thickness $L_{C}$ would be given by,

$$
T_{C}=\left(\frac{v}{g_{C}^{\prime}}\right)^{1 / 3}
$$


1 Note that this expression does not contain the Stokes settling velocity $\left(w_{S}\right)$. This resulting time2 scale $\left(T_{C}\right)$, is the fundamental time-scale for the convective sedimentary instability, and has been 3 used in a number of important recent studies to non-dimensionalize the time-scales of various 4 numerical simulations (Burns \& Meiburg 2012, 2015; Shao et al., 2017).Their resulting 3D 5 simulations suggest that it takes of order 100 time-scales for fully developed settling-driven convection to develop. This convective time-scale will subsequently be used in this paper to determine the experimental length-scale over which sediment is lost from the bottom of a surface

8 plume. From this point onwards, $c_{t}$ will be defined as the dimensionless multiple of the time in 9 Equation (9) that takes for settling-driven convection to develop, and the value of $c_{t}$ will be 10 determined experimentally. It will be assumed that the sedimentary convective time-scale of 11 Burns \& Meiburg $(2012,2015)$ is the relevant time-scale for sediment to be lost from the sharp 12 density interface beneath the overflow so that $T_{S}=T_{C}$. With this assumption, Equations (3) and 13 (9) can be combined to estimate a propagation length-scale $\left(L_{\text {prop }}\right)$ for the gravity current as,

$$
L_{\text {prop }} \sim \operatorname{Fr}\left(g \frac{\Delta \rho_{S}}{\rho_{0}} H\left(1-\frac{1}{R_{\rho}}\right)\right)^{1 / 2} v^{1 / 3}\left(g \frac{\Delta \rho_{C}}{\rho_{0}}\right)^{-2 / 3}
$$

To see the dependence on $R_{\rho}$ even more clearly, by keeping the salinity anomaly $\Delta \rho_{S}$ constant and assuming $\mathrm{Fr} \sim 1$, then two dimensional constants are introduced, $c_{1}=\left(g \Delta \rho_{S} H / \rho_{0}\right)^{1 / 2}$ and $c_{2}$ $19=v^{l / 3}\left(g \Delta \rho_{S} / \rho_{0}\right)^{-2 / 3}$, with units of $\mathrm{m} \mathrm{s}^{-1}$ (speed) and $\mathrm{s}$ (time) respectively. This reduces the propagation length-scale to a simple function of $R_{\rho}$ as,

$$
L_{\text {prop }}=c_{1} c_{2} c_{t}\left(1-\frac{1}{R_{\rho}}\right)^{1 / 2} R_{\rho}^{3 \cdot / 3}
$$

24 where the combined coefficients $c_{1} c_{2}$ (assuming $\rho \approx \rho_{0}$ ) can be furthermore simplified to provide 25 a scale constant (with units of $\mathrm{m}$ ) as,

$$
c_{1} c_{2}=H^{1 / 2} v^{1 / 3}\left(g \frac{\Delta \rho_{S}}{\rho}\right)^{-1 / 6}
$$

The propagation length-scale $\left(L_{p r o p}\right)$ in Equation (11) goes to zero as $R_{\rho}$ approaches unity (when 
1 the case of $R_{\rho}<1$ an underflow would occur as the plume would be initially denser than the 2 receiving environment.

\section{RESULTS}

\section{Evolution of the current is related to density ratio}

The striking differences in the behaviour of the sediment-laden current can be seen in the 8 photograph time series from experiments (Figs. 4, 5 and 6). In particular, the propagation lengthscale of the plume is a strong function of the density ratio and decreases as $R_{\rho}$ gets close to one. Secondary turbidity currents are also seen to form most strongly as $R_{\rho}$ gets close to unity. In all

11 cases, the changes in behaviour are tied to the vigour of settling-driven convection that strongly increases as $R_{\rho}$ decreases towards unity.

The speed at which sediment-laden plumes sink beneath the surface plume increases dramatically with decreasing $R_{\rho}$ (Fig. 4). The series of photographs in Figure 4 depicts the

17 The higher value $R_{\rho}=3.051$ in Figures 4A to $4 \mathrm{~J}$ means there is less sediment, and results in weak 18 settling-driven convection. On the other hand for a smaller density ratio of $R_{\rho}=1.48$, Figures $4 \mathrm{~K}$ to $4 \mathrm{~T}$ depicts a very vigorous mode of settling-driven convection, which resulted in the rapid sinking of distinct finger-like structures. Figures $4 \mathrm{~J}$ and $4 \mathrm{Q}$ display evidence of settling to the

21 bottom after $270 \mathrm{~s}$ and $180 \mathrm{~s}$ respectively. These corresponds to vertical velocities of

22 approximately $w=0.14 \times 10^{-3} \mathrm{~m} \mathrm{~s}^{-1}$ for $R_{\rho}=3.051$, whereas for $R_{\rho}=1.48$ the vertical velocity is

23 faster with $w=2.2 \times 10^{-3} \mathrm{~m} \mathrm{~s}^{-1}$. For comparison, the Stokes settling velocity of an individual

24 particle is $7.7 \times 10^{-5} \mathrm{~m} \mathrm{~s}^{-1}$, and hence the estimated time from the Stoke settling velocity for a

25 single $\mathrm{SiC}$ particle to go from the top to the bottom of the experimental tank is $2 \mathrm{hr}$. Thus, Figure

264 shows that settling-driven convection at low density ratios has a substantial effect on 27 increasing the downward velocity of collections of $\mathrm{SiC}$ particles.

The shapes of the sinking sediment-laden fingers also change with increasing density ratio as

30 displayed in Figure 5. These close-up images illustrate the reduction in width and velocity of the convective sediment fingers as density ratio increases. Figure 5 displays zoomed in photos, taken 
1 every $30 \mathrm{~s}$, and shows weaker settling-driven convection for $R_{\rho}=4.575$ and a much more vigorous settling-driven convection for $R_{\rho}=1.229$. The vertical distance moved by fingers between images indicate faster velocities for $R_{\rho}=1.229$, where the fingers of sediment were wider and formed earlier (compared to $R_{\rho}=4.575$ ). The vertical velocity of the small plumes (for $R_{\rho}=4.575$ ) and the large fingers (for $R_{\rho}=1.229$ ) can be estimated as $w=6 \times 10^{-4} \mathrm{~m} \mathrm{~s}^{-1}$ and $w=$ $3 \times 10^{-3} \mathrm{~m} \mathrm{~s}^{-1}$ respectively (similar to Figure 4). A general trend in both Figures 4 and 5 is that as density ratio decreases towards unity, the surface current moved slower horizontally and the

8 formation of finger-like structures occurred earlier. With the increase in the mass of particles for lower $R_{\rho}$, the sediment settled faster as well as entraining water out of the current (as described before by Maxworthy (1999) and Sutherland et al. (2018)). Therefore, the head of the current

11 decreased in size and could eventually stop before the end of the tank if settling-driven convection was vigorous enough.

In many experiments, the intense settling-driven convection could form a turbid interflow or an intense turbidity current beneath the buoyant plume (Fig. 6). The series of photos in Figure 6, taken every $60 \mathrm{~s}$, displays these two distinct behaviours of flow for $R_{\rho}=1.172$ and $R_{\rho}=1.054$. In

17 both cases the current moved visibly slower (in the horizontal direction) than those discussed

18 earlier in Figure 5. As can be seen in Figure 6, both currents never reached the end of the tank and stopped before passing $1.5 \mathrm{~m}$, as the sediments settled rapidly due to the very vigorous settling-driven convection of $\mathrm{SiC}$ particles. In Figures $6 \mathrm{E}$ to $6 \mathrm{~J}$, corresponding to $R_{\rho}=1.172$,

21 after the overflow stopped at $L_{\text {prop }}=1.3 \mathrm{~m}$, it was interesting to observe the emergence of an 22 interflow below the initial overflow, which lasted for a long time. In this case not only the 23 sediment particles were falling down but they were also dragging water down with them. 24 However, these plumes were not heavy enough to plunge down to the very bottom of the tank. 25 Therefore, the amount of water that the plume carried with itself became significant (similar 26 observations are reported in Sutherland et al. 2018). On the other hand, for $R_{\rho}=1.054$ the 27 overflow stopped at a shorter distance of $L_{\text {prop }}=0.75 \mathrm{~m}$ and an underflow occurred shortly after.

28 This formation of a secondary underflow is consistent with observations first made by 29 Maxworthy (1999). 
The difference between the horizontal velocities of the buoyant plumes with various density ratios can be determined from a series of horizontal photos of the top $0.127 \mathrm{~m}$ of the overflow (Fig.7). The standard equation for the velocity in a buoyant plume (Eq. 3) predicted that the horizontal velocity would scale with density ratio as $U \sim\left(1-1 / R_{\rho}\right)^{1 / 2}$, i.e. the velocity decreases as $R_{\rho}$ approaches one, where there is no density difference. Equation (3) is governed by the dimensionless Froude number, which has usually been found to be between 0.5 to 1 in many previous experiments (i.e. Turner, 1979; Simpson, 1982; Gladstone \& Pritchard, 2010; Snow \& 8 Sutherland, 2014). As an illustration of this, three cases of $R_{\rho}=\infty, 2.492$ and 1.172 are considered here. The speed of the overflow was determined by fitting the best line to the front of the current in each stack of images. The speeds corresponding to the density ratios under 11 consideration were $U_{(R \rho=\infty)}=0.0279 \mathrm{~m} \mathrm{~s}^{-1}, U_{(R \rho=2.492)}=0.0246 \mathrm{~m} \mathrm{~s}^{-1}$ and $U_{(R \rho=1.172)}=0.0068 \mathrm{~m}$ $12 \mathrm{~s}^{-1}$. Note that for $R_{\rho}=1.172$ the gravity current stopped at $L_{\text {prop }}=1.3 \mathrm{~m}$, as was also displayed in 13 Figure 6. The comparison of the initial speed of the propagating overflow in the three figures 14 shows a faster speed for the larger density ratios, consistent with the scaling of Equation (3). 15 Using the observed experimental speeds, Equation (3) then determines the Froude number for $R_{\rho}$ $16=\infty$ to be $\operatorname{Fr}_{(R \rho=\infty)}=0.820$. Furthermore, estimations of the Froude number based on Equation (3) 17 for $R_{\rho}=2.492$ and 1.172 are $\operatorname{Fr}_{(R \rho=2.492)}=0.880$ and $\operatorname{Fr}_{(R \rho=1.172)}=0.506$ respectively. These 18 estimates of the dimensionless Froude numbers are all within the expected range of 0.5 to 1 from 19 previous experiments (i.e. Turner, 1979; Simpson, 1982; Gladstone \& Pritchard, 2010). It is also noteworthy in Figure 7 that in all three cases there appears to be no influence from the end wall on these estimates of propagation speed, as the horizontal velocity is constant with time up to the point where plumes hit the wall.

There is very good quantitative agreement between the theoretical prediction of Equation (11) and experimental results of the propagation length-scale of the sediment-laden gravity current as a function of density ratio (Fig. 8). This is the most important result in this paper, and Figure 8

27 shows that the propagation length-scale decreases to zero as density ratio decreases to one. For $R_{\rho}$ less than one a plunging flow would occur. The data points are surrounded by two curves in blue, which provides upper and lower bounds on the constants $c_{1}$ and $c_{2}$ in Equation (12). For 30 experimental conditions in the current study, where $2.9 \mathrm{~kg} \mathrm{~m}^{-3} \leq \Delta \rho_{S} \leq 3.7 \mathrm{~kg} \mathrm{~m}^{-3}$, the two 31 constants are in the range of $0.0380 \leq c_{1} \leq 0.0619 \mathrm{~m} \mathrm{~s}^{-1}$ and $0.0967 \leq c_{2} \leq 0.1848 \mathrm{~s}$, so that the 
1 product of $c_{\text {lavg }} c_{2 a v g}=0.0069 \mathrm{~m}$. As outlined earlier, previous numerical simulations of Burns \& 2 Meiburg $(2012,2015)$ suggest that it will take several hundred time-scales for large "finger" 3 instabilities to develop, and so in Figure 8 the blue theoretical curves are plotted to have values 4 of $c_{t}=440$ and 500. These two values bracket the observations well and are consistent with the expectation that $c_{t}$ is of order 100 . For typical values of $c_{1}$ and $c_{2}$ in laboratory conditions, with 1

$6<R_{\rho}<2$, the propagation length-scale is predicted to be $0<L_{\text {prop }} \leq 1.83 \mathrm{~m}$. Furthermore, for any $7 \quad R_{\rho}>1.3$ in the conducted experiments the observed propagation length-scale $\left(L_{p r o p}\right)$ was limited 8 to the tank length of $1.83 \mathrm{~m}$. It is important to note that all these observations have length-scales dramatically smaller than the prediction of $L_{\text {prop }}$ based on the Stokes particle settling rate in

11 under the influence of settling-driven convection process.

\section{DISCUSSION}

\section{Density ratio predicts the sedimentation pattern}

The fluid dynamics of the convective sedimentation beneath a buoyant river plume are strongly influenced by the density ratio, as summarized in Figure 9. In the experiments with lower sediment concentrations $\left(R_{\rho}>2\right)$, weak settling-driven convection and slow sinking of particles (e.g. $w=6 \times 10^{-4} \mathrm{~m} \mathrm{~s}^{-1}$ ) were observed, in experiments that lasted for a long duration of time (e.g. $\mathrm{t}=45 \mathrm{~min}$ ). On the other hand, when $1.3<R_{\rho}<2$ fingers of sediment were rapidly sinking with much greater vertical velocities of $w=0.3 \times 10^{-3} \mathrm{~m} \mathrm{~s}^{-1}$ under the direct effect of strong and vigorous settling-driven convection. In both of the above-mentioned cases the current reached the end wall, so that $L_{\text {prop }}=1.83 \mathrm{~m}$ for these experiments in Figure 8 . For higher

24 sediment concentrations with $1.17<R_{\rho}<1.23$, the surface plume stopped well before reaching the end wall. In these cases, a slow moving sediment-laden interflow occurred beneath the surface plume. Finally, for cases where $R_{\rho}$ was very close to unity not only the surface flow

27 stopped, but also an intense underflow was observed. In a much longer tank, it is likely that all the flows would have stopped, and hence formed some sort of subsurface gravity current. However, it is noteworthy that the only intense secondary underflow occurred when $R_{\rho} \sim 1$. It is

30 very challenging to interpret isolated field observations beneath a river plume. Hence, the images 
1 field estimates of $R_{\rho}$ could provide a useful guidance for interpretation of data and the possible

2 design of future field observation campaigns.

The most important results of the current set of experiments is that Equation (11) quantifies the length-scale over which it is likely that a surface sediment-laden plume can transform into a subsurface turbidity current (Fig. 10). In lakes with smaller lengths than $L_{\text {prop }}$ the sediment is expected to rain down uniformly over the lake bed, possibly with some size fractionation with 8 larger particles closer to river mouth. However, if $L_{\text {prop }}$ is sufficiently small compared to the size of the lake, then a secondary turbidity current could form and deposit sediments far from the river mouth, which are often ponded in the deepest regions of the basin. These two forms of

11 sedimentation will result in quite different stratigraphy in lake beds, which can then be used to infer paleoclimate records of inflow events (Gilbert \& Butler, 2004; Cossu et al., 2015).

The mechanism of transforming a buoyant sediment-laden plume into a secondary turbidity current was first expressed by Maxworthy (1999) and greatly popularized in the sedimentology literature by Parsons et al. (2001). This process is often invoked as a potential mechanism by

17 which turbidity currents can form, given that typically sediment loads in rivers are not high 18 enough to directly form underflows (Mulder \& Syvitski, 1995; Mulder \& Chapron, 2011).

19 Equation (11) can now be used to rigorously quantify when secondary turbidity currents are 20 likely to form. The experimental observations and theoretical predictions in this study confirm 21 that the propagation length-scale of such a flow can dramatically change once density ratio gets 22 very close to unity and it scales as $L_{\text {prop }} \sim\left(1-1 / R_{\rho}\right)^{1 / 2} R_{\rho}^{2 / 3}$. When $R_{\rho}$ is less than one, an 23 underflow would form. It is expected that sediment-laden river inflows into lakes will typically 24 have much lower density ratios than in the coastal ocean, so that the behaviour of sedimentation and deposition scales will be very different for the same sediment load in a river (Fig. 9). When a river flows into a lake, the density difference arises due to the temperature anomaly (rather than 27 the salinity difference). The largest density anomaly expected in most lakes might be a $20{ }^{\circ} \mathrm{C}$ river flowing into a $10{ }^{\circ} \mathrm{C}$ lake, so that $g \Delta \rho_{S} / \rho=0.0146 \mathrm{~m} \mathrm{~s}^{-2}$. In contrast, for a fresh river entering the ocean saline water the reduced gravity would be of order $g \Delta \rho_{S} / \rho=0.294 \mathrm{~m} \mathrm{~s}^{-2}$, i.e.

30 at least 20 times greater. Thus, for the same sediment load, $R_{\rho}$ is always much larger than one in 31 the ocean and much closer to one in a lake. Underflows are frequently observed in rivers entering 
1 lakes (see for example Fig.19D-2 in Talling et al. 2013, and Cossu et al. 2015), whereas only very rarely do rivers have enough sediment load in the ocean to form underflows (Mulder \& Syvitski, 1995; Mulder \& Chapron, 2011). As an example, Hughes Clarke et al. (2014) describe typical sediment concentrations as usually being less than $0.07 \mathrm{~kg} \mathrm{~m}^{-3}$ in the Squamish River. In the coastal ocean this is clearly insufficient to form an underflow directly, and the estimated density ratio would be $R_{\rho} \sim 25 \mathrm{~kg} \mathrm{~m}^{-3} / 0.07 \mathrm{~kg} \mathrm{~m}^{-3} \sim 350$. In contrast, if this same river flowed into a thermally stratified lake with a large $10{ }^{\circ} \mathrm{C}$ difference across the thermocline, it would have $R_{\rho} \sim 1.5 \mathrm{~kg} \mathrm{~m}^{-3} / 0.07 \mathrm{~kg} \mathrm{~m}^{-3} \sim 20$, and could potentially even have $R_{\rho} \sim 1$, if the temperature difference between river and lake was less than $1{ }^{\circ} \mathrm{C}$. For $R_{\rho}>>1$ then $L_{\text {prop }} \sim R_{\rho}{ }^{2 / 3}$, so the difference in propagation length between $R_{\rho}=20$ and 350 is a factor of 100 , indicating a substantial difference in the likely deposition behaviour between a lake and the ocean.

\section{From laboratory experiments to the field}

The idea from Parsons et al. (2001) that settling-driven convection can lead to formation of turbidity currents has been often invoked to explain field observations of turbidity currents, but only a few field studies detail some of the causal links. For instance, Hizzett et al. (2017) noted 17 that the occurrence of turbidity current below the delta of the Squamish River correlated best 18 with the presence of sediment-laden river plumes, rather than slope failures on the delta. In addition, Schue et al. (2015) studied a sediment-laden river plume flowing into a thermally stratified Alpine lake, and observed (using acoustic backscatter) that the vertical velocity of a descending sediment layer below a river plume was an order of magnitude greater than Stokes settling velocities, consistent with the experimental plumes in Figure 4. Furthermore, Giovanoli (1990) studied the transport of sediments from Rhône River flowing into Lake Geneva as an interflow. As mentioned in this study, the sediment concentration in the Rhône River is in the range of $10-5000 \mathrm{mg} \mathrm{l}^{-1}$. With the assumption that there is a $10^{\circ} \mathrm{C}$ temperature difference between the two layers, it would result in a density ratio within the range of $0.3<R_{\rho}<150\left(R_{\rho} \sim\right.$ $1.5 \mathrm{~kg} \mathrm{~m}^{-3} / 5 \mathrm{~kg} \mathrm{~m}^{-3} \sim 0.3$ and $\left.R_{\rho} \sim 1.5 \mathrm{~kg} \mathrm{~m}^{-3} / 0.01 \mathrm{~kg} \mathrm{~m}^{-3} \sim 150\right)$. When $R_{\rho}<1$ in Rhône River underflows would form, while for $1<R_{\rho}<150$ there is the potential that settling-driven convection could be important underneath the Rhône River. 
Rivers only occasionally have sufficient suspended sediment to have a density that exceeds 2 that of sea water, when they would immediately form plunging flows (Mulder \& Syvitski, 1995).

3 Faster flowing rivers are able to erode and carry more sediment, so it is expected that if 4 underflows could form, it is during flooding events. Empirical data has often be used to find a 5 relationship between the suspended sediment concentration $\left(C_{s}\right.$ with units of $\left.\mathrm{kg} \mathrm{m}^{-3}\right)$ and the flow 6 rate of the river $\left(Q\right.$ with units of $\left.\mathrm{m}^{3} \mathrm{~s}^{-1}\right)$ of the form

$$
C_{S}=a Q^{b}
$$

where $a$ and $b$ are empirical rating coefficients. Furthermore, Mulder \& Syvitski (1995) show 11 that the increased concentration of sediment during a flood $\left(C_{s \text { Flood }}\right)$ is related to the average 12 concentration $C_{s \text { Average }}$ as

$$
C_{S \text { Flood }}=C_{S \text { Average }}\left(\frac{Q_{\text {Flood }}}{Q_{\text {Average }}}\right)^{b}
$$

where $Q_{\text {Flood }}$ and $Q_{\text {Average }}$ are the flow rates during a flood and average conditions. An underflow

17 would occur if $C_{s}>\Delta \rho_{\text {SeaWater }}$. For typical $15{ }^{\circ} \mathrm{C}$ and 35 ppt salinity seawater the density

18 difference with fresh water is $\Delta \rho_{\text {SeaWater }}=25.9 \mathrm{~kg} \mathrm{~m}^{-3}$ and hence, an underflow happens when $C_{s}$

$19>25.9 \mathrm{~kg} \mathrm{~m}^{-3}$. Mulder \& Syvitski (1995) show that a large number of "moderately dirty" rivers

20 could produce underflows (i.e. $R_{\rho}<1$ ) with $b<1$ (Table 3 in Mulder \& Syvitski 1995). For

21 "moderately clean" rivers on the other hand, many would need to have $1<b \leq 1.5$ (Table 4 in

22 Mulder \& Syvitski 1995) to occasionally produce underflows, whereas "relatively clean" rivers

23 would need $1.5<b \leq 2$ (Table 5 in Mulder \& Syvitski 1995) to ever be able to form underflows.

One of the key results of this experiment was to identify that there is a distance over which a surface buoyant plume would lose most of its sediment. Hence, rather than an underflow

27 requiring that a river be denser than seawater, previous papers have suggested that settlingdriven convection should allow the sediment in many rivers to be able to convert to a turbid underflow (i.e. Parsons et al., 2001). In order to use the scaling of Equation (14) to estimate the length-scale of propagation of a buoyant plume, the density ratio can be re-written as 


$$
R_{\rho}=\frac{\Delta \rho_{S}}{\Delta \rho_{C}}=\frac{\Delta \rho_{\text {SeaWater }}}{C_{S \text { Flood }}} \times\left(\frac{Q_{\text {Average }}}{Q_{\text {Flood }}}\right)^{b}
$$

3 Therefore, while the condition of Mulder \& Syvitski (1995) requires $R_{\rho} \leq 1$ for underflow

4 formation, the experiments conducted in this study show that in many cases a secondary turbidity

5 current can form in a distance that increases with $R_{\rho}$.

It is helpful to consider when there might be sufficient sediment load in the Squamish River in BC, Canada to form underflows (Fig. 11). This particular river is a good example of a sedimentladen river that is known to form periodic underflows (Hizzett et al. 2017). Data from Table 3 in Mulder \& Syvitski (1995) suggests that $C_{s \text { Average }}=1 \mathrm{~kg} \mathrm{~m}^{-3}, Q_{\text {Average }}=58 \mathrm{~m}^{3} \mathrm{~s}^{-1}$ and $b \leq 1$ for this river. In this case, assuming $b=1$, then when $Q_{\text {Flood }}=1502 \mathrm{~m}^{3} \mathrm{~s}^{-1}$, the ratio $Q_{\text {Flood }} / Q_{\text {Average }}=$ 25.9 would predict $R_{\rho}=1$. Any higher flow rate would have $R_{\rho}<1$ and so for all higher values of $Q$ a plunging flow would form. For normal flow conditions however, the density of suspended sediment is $C_{s \text { Average }}=1 \mathrm{~kg} \mathrm{~m}^{-3}$, which would predict $R_{\rho}=25.9$. Hence, it is instructive to plot the predicted length-scale $\left(L_{p r o p}\right)$ as a function of flow rate values $(Q)$ in Figure 11. In this figure, depth of the river is assumed to be $H=10 \mathrm{~m}$ (note that the constant in Equation (11) depends on $H^{1 / 2}$ and hence the result is not very sensitive to exact choice of this values, which would also fluctuate with tides). In Using Equation (11), the predicted length-scale of deposition for the Squamish River is $136 \mathrm{~m}$ for the average flow rate value of $Q_{\text {Average }}=58 \mathrm{~m}^{3} \mathrm{~s}^{-1}$, and up to $1-2$ $\mathrm{km}$ for lower flow rate values (Fig. 11). While there are no direct observations of settling-driven convection below the Squamish River, the predicted length-scales of 100s to 1000s of meters are broadly consistent with the distributions of sediment from the Squamish River within Howe Sound (i.e. Figure 2 in Gales et al. 2018). The exact relationship between $R_{\rho}$ and $Q$ for a specific river would require more research - for instance the average value of observed suspended sediment concentrations made by Hughes Clarke et al. (2014) was $0.07 \mathrm{~kg} \mathrm{~m}^{-3}$ in the Squamish River, notably less than the value of $C_{s \text { Average }}=1 \mathrm{~kg} \mathrm{~m}^{-3}$ described by Mulder \& Syvitski (1995).

\section{Important differences between laboratory experiments and the field}

The real world is much more complicated than the idealized experiments performed in this paper. The major benefit of laboratory experiments is that they can be used to study one specific process in isolation so that the controlling parameters can be quantified. On the other hand, the 
1 disadvantage is that when applying such scaling of the length-scale to a field setting, there may 2 be many other processes that could also be important. Hence, it is critical to discuss the 3 significant differences that might influence the interpretation of results in this paper. One 4 important difference is that the current set of experiments had a finite volume of sediment-laden 5 fluid that entered the ambient - these are the so-called "dam break" experiments and are widely used in fluid dynamics laboratory experiments (i.e. Turner, 1979; Simpson, 1982; Gladstone \&

7 Pritchard, 2010). A real river however has a constant inflow, with new material continuously 8 being pushed out from the river mouth. Therefore, even if most of the sediment is settling out 9 from the river plume in a distance $L_{\text {prop }}$, the surface layer would still be pushed out by the 10 continuous supply of water. Hence, the surface plume could continue to move out into the water 11 body many kilometers, even after settling has occurred. Thus, the length-scales shown in Figure 12 11B are probably lower bounds on what the length-scale of the surface plume would look like in 13 the field. In addition, Equation (11) implicitly assumes that the plume only spreads in one 14 dimension, as in the laboratory. This is probably a reasonable assumption for the Squamish River 15 spreading in the long fjord of Howe Sound, but in many coastal settings, river plumes are 16 unconstrained and will spread in two-dimensions (Horner-Devine et al., 2015). Secondary 17 turbidity currents are also more likely to occur when there is a sloping bottom, as opposed to the 18 uniform depth in these experiments. For instance the experimental setup in the studies made by 19 Parsons et al. (2001), Snow \& Sutherland (2014) and Sutherland et al. (2018) all included a 20 sloping ramp, which would probably increase the tendency to form turbidity currents beneath an 21 overflow.

Another critical process that occurs when fine river sediments meet the ocean is flocculation, which can also dramatically increase settling rates as flocs of particles sink faster than an individual particle. Flocculation is typically promoted at the pycnocline due to ionic exchange and other processes, so where fresh water enters a saline body, flocculation may be more likely.

27 The increases in settling of sediment particles by flocculation could be occurring at the same 28 time as settling-driven convection, so future work would need to determine the relative 29 importance of such processes in estuaries. In real rivers there will also be a distribution of 30 sediment particle size, rather than the uniform particles used in this study. Larger particles can 31 sink into the "nose region" of Figure 2B faster than small particles, so there is weak dependence 
1 on the instability time-scale of Equation (9), as observed in the 3D simulations of Burns \& 2 Meiburg (2015) and experimental observations of Sutherland et al. (2018). While some 3 numerical work (i.e., Burns \& Meiburg, 2012, 2015; Yu et al., 2014, 2015) and experimental 4 studies (Sutherland et al., 2018) have suggested a weak dependence of the vigour of settling5 driven convection on particle size, this remains an important area of future work. The main effect of a particle distribution will be some degree of fractionation of particles, with the larger particles being deposited closer to river mouth, and smaller particles settling at great differences 8 from river mouth.

Tidal currents have also been shown to be somewhat important in triggering of turbidity 11 currents in locations in British Columbia such as the Squamish River (Clare et al., 2016) and the 12 Fraser delta (Ayranci et al., 2012; Lintern et al., 2016). While Clare et al. (2016) found that 13 surface sediment-laden plumes at Squamish were linked to $\sim 70 \%$ of all turbidity currents; the 14 precise timing was also strongly affected by tidal elevation. At low tides at Squamish, more (and coarser) sediment was flushed off the delta top, which increased the sediment flux and had

16 higher settling rate due to coarser grains being transported. This tidal influence overprints the 17 original signature of river discharge (Clare et al., 2016). At low tides, it is also possible that the 18 shallow water depth may also promote formation of turbidity currents as there would be less 19 dilution of the sediment-laden convective fingers, similar to how the sloping ramp promoted the 20 formation of turbidity currents in experiments of Parsons et al. (2001), Snow \& Sutherland 21 (2014) and Sutherland et al. (2018).

\section{Possible applications of experiments to other systems}

A recent paper by Stack et al. (2018) has tried to extrapolate some of the dynamics of sediment-laden rivers on Earth to understand ancient geological formations on Mars that possibly formed underwater. Specifically when trying to explain the geology of the Murray

27 formation they speculate about the conditions under which an ancient Martian river could form an underflow in the Gale crater. A starting point for their discussion is that the evidence for geological deposits associated with a plunging river plume implies that the density of the river

30 water be greater than that of the receiving waters (i.e. that $R_{\rho} \leq 1$ ). From various estimates of 31 the possible sediment load in river they draw inferences as to how salty the water body could 
1 have been. The analysis in this paper hopefully shows that in many situations plunging 2 underflows can also form for $R_{\rho}>1$ due to the active settling-driven convection at the base of the 3 overflow. Hence, the estimates by Stack et al. (2018) of the salinity of ancient water bodies in 4 the Gale crater are possibly lower bounds, which have important implications for life on Mars.

A final area where the dynamics of settling-driven convection is relevant is in the dynamics of pyroclastic flows, especially in how a hot volcanic ash cloud might intrude into the thermally 8 stratified atmosphere. Indeed the current work is related to previous experiments of Carazzo \& Jellinek (2012, 2013), Manzella et al. (2015) and Scollo et al. (2017), who studied the dynamics of settling-driven convection in order to interpret field observations of ash-laden volcanic clouds.

11 In particular, geologists often wish to know the radius over which ash will deposit, as this has 12 important hazard prediction implications. Equation (11) could be used to help estimate this 13 radius - the major difference being that the air has a much lower viscosity than water, which will 14 tend to enhance the rate at which the instability forms. The video imagery provided in the 15 Supplementary material might further help interpret the finger like sediment plumes often seen in 16 field observations of volcanic ash clouds (Scollo et al., 2017).

\section{CONCLUSION}

The main finding of this paper is that settling-driven convection can result in the rapid loss of sediment below a buoyant plume. The length-scale of sediment deposition is determined by the

22 length-scale over which the plume propagates, and the faster sediment loss due to settling-driven 23 convection results in a far smaller propagation length-scale compared to a simple estimate made 24 by the Stokes settling velocity. The vertical settling of dense sediment-laden plumes was measured to be as much as 100 times that of the Stokes settling velocity of an individual particle. For density ratios close to unity, the propagation length-scale was small and an intense 27 underflow or interflow emerged, which propagated longer distance than the surface plume. 28 However, when density ratio was larger than one this length-scale increased as $R_{\rho}^{2 / 3}$. For a given 29 salt stratification in an estuary, or thermal stratification in a lake, the sediment difference 30 between the surface and deep layers will determine the strength of settling-driven convection. 31 The sediment load in a river can be estimated by using a rating curve for the sediment load as a 
1 function of river flow rate $(Q)$. Hence, it is possible to estimate the density ratio $\left(R_{\rho}\right)$ as a

2 function of $Q$ for a river flowing into a salty ocean. Equation (11) can then be used to predict the

3 length-scale over which sedimentation could occur, as was done in the example of the Squamish

4 River. In these oceanic cases it is reasonable to ignore temperature effects, as large salinity

5 differences dominate the density differences. To make the same estimates using Equation (11)

6 for a lake, it would also require that the temperature of the river and the seasonal thermal

7 stratification of the lake be known. For example, Cossu et al. (2015) discussed how the

8 seasonality in sediment loading in rivers and changes of the thermal stratification in an alpine

9 lake could greatly influence whether overflows, interflows or underflows occurred. Hopefully,

10 future research into these processes will include measurements of the density ratio, and the

11 design of field observations can be guided by the predictions of Equation (11) and the time-lapse

12 movies contained in the Supplemental section.

13

\section{ACKNOWLEDGMENTS}

15 We acknowledge constructive comments from Dr. Mike Clare and two anonymous reviewers

16 that were very helpful in revising this article. M. G. Wells was funded through the NSERC

17 Discovery program grant (RGPIN-2016-06542). 


\section{NOMENCLATURE}

2

$3 a \quad$ Empirical rating coefficient

$4 \quad b \quad$ Empirical rating coefficient

$5 \quad C \quad$ Average concentration of the flow $\left(\mathrm{kg} \mathrm{m}^{-3}\right)$

$6 C_{s} \quad$ Concentration of suspended sediment $\left(\mathrm{kg} \mathrm{m}^{-3}\right)$

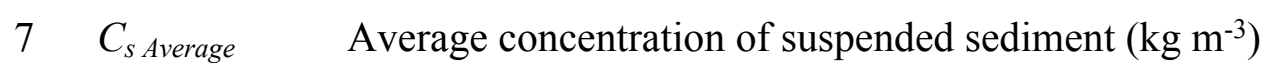

$8 C_{s \text { Flood }} \quad$ Concentration of suspended sediment during a flood $\left(\mathrm{kg} \mathrm{m}^{-3}\right)$

$9 c_{t} \quad$ Dimensionless multiple of time that takes for settling-driven convection to

10 develop

$11 C_{0} \quad$ Initial concentration of the flow $\left(\mathrm{kg} \mathrm{m}^{-3}\right)$

$12 \quad c_{1} \quad 1^{\text {st }}$ dimensional constant $\left(\mathrm{m} \mathrm{s}^{-1}\right)$

$13 \quad c_{\text {lavg }} \quad$ Average value of the $1^{\text {st }}$ dimensional constants $\left(\mathrm{m} \mathrm{s}^{-1}\right)$

$14 \quad c_{2} \quad 2^{\text {nd }}$ dimensional constant (s)

$15 c_{2 a v g} \quad$ Average value of the $2^{\text {nd }}$ dimensional constants (s)

16 Fr Froude number

$17 g \quad$ Gravitational acceleration $\left(9.81 \mathrm{~m} \mathrm{~s}^{-2}\right)$

$18 \quad g^{\prime} \quad$ Reduced gravity $\left(\mathrm{m} \mathrm{s}^{-2}\right)$

$19 \quad g_{C}^{\prime} \quad$ Reduced gravity in terms of density difference due to the added sediment $\left(\mathrm{m} \mathrm{s}^{-2}\right)$

$20 \mathrm{Gr} \quad$ Grashof number

$21 H \quad$ Thickness of the current (m)

$22 \bar{H} \quad$ Mean thickness of the current $(\mathrm{m})$

$23 \quad L_{C} \quad$ Thickness of the nose region (m)

$24 L_{\text {prop }} \quad$ Propagation length-scale of the current (m)

$25 \quad m_{C} \quad$ Mass of sediment particles $(\mathrm{kg})$

$26 \quad m_{\text {comp }} \quad$ Mass of the water in the small compartment $(\mathrm{kg})$

$27 Q \quad$ The flow rate of a river $\left(\mathrm{m}^{3} \mathrm{~s}^{-1}\right)$

$28 \quad Q_{\text {Average }} \quad$ Average flow rate of a river $\left(\mathrm{m}^{3} \mathrm{~s}^{-1}\right)$

$29 Q_{\text {Flood }} \quad$ Flow rate of a river during flood $\left(\mathrm{m}^{3} \mathrm{~s}^{-1}\right)$

$30 \operatorname{Re} \quad$ Reynolds number

$31 R_{\rho} \quad$ Density ratio 


\section{NOMENCLATURE CONTINUED}

2

$3 T_{S}$

$4 t$

$5 t_{\text {comp }}$

$6 t_{S}$

$7 t_{0}$

$8 U$

$9 V_{\text {comp }}$

$10 w$

$11 w_{S}$

$12 \Delta \rho$

$13 \Delta \rho_{C}$

$14 \Delta \rho_{S}$

$15 \Delta \rho_{\text {SeaWater }}$

$16 \Delta t$

$17 \varphi$

$18 \gamma$

$19 v$

$20 \rho$

$21 \rho_{C}$

$22 \rho_{\text {comp }}$

$23 \rho_{f}$

$24 \rho_{S}$

$25 \rho_{S i C}$

$26 \rho_{0}$

27

28
Settling time-scale of sediment particles (s)

Time (s)

Temperature of the small compartment $\left({ }^{\circ} \mathrm{C}\right)$

Temperature of the saline ambient $\left({ }^{\circ} \mathrm{C}\right)$

Time corresponding to the initial stable density profile (s)

Horizontal velocity of the current $\left(\mathrm{m} \mathrm{s}^{-1}\right)$

Volume of the compartment $\left(\mathrm{m}^{3}\right)$

Vertical velocity of the fluid in the nose region $\left(\mathrm{m} \mathrm{s}^{-1}\right)$

Stokes settling velocity of sediment particles $\left(\mathrm{m} \mathrm{s}^{-1}\right)$

Density difference between the current and the saline ambient $\left(\mathrm{kg} \mathrm{m}^{-3}\right)$

Density differences due to the added sediment $\left(\mathrm{kg} \mathrm{m}^{-3}\right)$

Density differences due to the added salt $\left(\mathrm{kg} \mathrm{m}^{-3}\right)$

Density difference due to the added salt for sea water at $15^{\circ} \mathrm{C}$

Elapsed time between the stable and the unstable density profiles (s)

Mass concentration of sediment particles $\left(\mathrm{kg} \mathrm{kg}^{-1}\right)$

Density expansion coefficient for SiC particles

Coefficient of kinematic viscosity of fresh water at $20{ }^{\circ} \mathrm{C}\left(10^{-6} \mathrm{~m}^{2} \mathrm{~s}^{-1}\right)$

Average density between the current and the saline ambient $\left(\mathrm{kg} \mathrm{m}^{-3}\right)$

Density of the sediment-laden water $\left(\mathrm{kg} \mathrm{m}^{-3}\right)$

Density of the small compartment before adding sediment $\left(\mathrm{kg} \mathrm{m}^{-3}\right)$

Total density of a fluid $\left(\mathrm{kg} \mathrm{m}^{-3}\right)$

Density of the saline ambient $\left(\mathrm{kg} \mathrm{m}^{-3}\right)$

Density of SiC particles $\left(3210 \mathrm{~kg} \mathrm{~m}^{-3}\right)$

Density of clear fresh water at $20^{\circ} \mathrm{C}\left(998.2 \mathrm{~kg} \mathrm{~m}^{-3}\right)$ 


\section{REFERENCES}

Ayranci, K., Lintern, D.G., Hill, P.R. and Dashtgard, S.E. (2012) Tide-supported gravity flows on the upper delta front, Fraser River delta, Canada. Mar. Geol., 326, 166 - 170.

Benjamin, T.B. (1968) Gravity currents and related phenomena. J. Fluid Mech., 31, 209 - 248.

Burns, P. and Meiburg, E. (2012) Sediment-laden fresh water above salt water: Linear stability analysis. J. Fluid Mech., 691, 279 - 314.

Burns, P. and Meiburg, E. (2015) Sediment-laden fresh water above salt water: Nonlinear stability analysis. J. Fluid Mech., 762, 156 - 195.

Carazzo, G. and Jellinek, A.M. (2012) A new view of the dynamics, stability and longevity of volcanic clouds. Earth Planet. Sci. Lett., 325 - 326, 39 - 51.

Carazzo, G. and Jellinek, A.M. (2013) Particle sedimentation and diffusive convection in volcanic ash-clouds. J. Geophys. Res. Solid Earth, 18, 1420 - 1437, doi:10.1002/jgrb.50155.

Chen, C.F. (1997) Particle flux through sediment fingers. Deep Sea Res., 44 (9 - 10), 1645 1654.

Clare, M.A., Clarke, J.H., Talling, P.J., Cartigny, M.J.B. and Pratomo, D.G. (2016) Preconditioning and triggering of offshore slope failures and turbidity currents revealed by most detailed monitoring yet at a fjord-head delta. Earth Planet. Sci. Lett., 450, $208-220$.

Cossu, R., Forrest A.L., Roop, H.A., Dunbar, G.B., Vandergoes, M.J., Levy, R.H., Stumoner, P. and Schladow, S. G. (2015) Seasonal variability in turbidity currents in Lake Ohau, New Zealand, and their influence on sedimentation. Mar. Freshwater Res., doi:10.1071/MF15043.

Davarpanah Jazi, S. and Wells, M.G. (2016) Enhanced sedimentation beneath particle-laden flows in lakes and the ocean due to double-diffusive convection. Geophys. Res. Lett., 43 (20), 10883 - 10890, doi: 10.1002/2016GL069547.

Forel, F.A. (1885) Les ravins sous-lacustres des fleuves glaciaires. Comptes Rendus de l'Académie des Sciences de Paris: 1-3.

Geyer, W.R., Hill, P.S. and Kineke, G.C. (2004) The transport, transformation and dispersal of sediment by buoyant coastal flows. Cont. Shelf Res., 1212 (24), 927 - 949.

Gilbert, R. and Butler, R.D. (2004) The physical limnology and sedimentology of Meziadin Lake, northern British Columbia, Canada. Arct. Antarct. Alp. Res., 36 (1), 33 - 41. 
Giovanoli, F. (1990) Horizontal transport and sedimentation by interflows and turbidity currents in Lake Geneva. In Large Lakes, edited by Tilzer, M. M. and Serruya, C., pp. 175 - 195, Springer, Berlin.

Gladstone, C. and Pritchard, D. (2010) Patterns of deposition from experimental turbidity currents with reversing buoyancy. Sedimentology, 57, $53-84$.

Green, T. (1987) The importance of double diffusion to the settling of suspended material. Sedimentology, 34, $319-331$.

Hill, P.S., Milligan, T.G. and Geyer, W.R. (2000) Controls on effective settling velocity of suspended sediment in the Eel River flood plume, Cont. Shelf Res., 20 (16), 2095 - 2111.

Hill, P.R., Conway, K., Lintern, D.G., Meulé, S., Picard, K. and Barrie, J.V. (2008) Sedimentary processes and sediment dispersal in the southern Strait of Georgia, BC, Canada. Mar. Environ. Res., 66, S39 - S48.

Hizzett, J.L., Hughes Clarke, J.E., Sumner, E.J., Cartigny, M.J.B., Talling, P. J. and Clare, M.A. (2017) Which triggers produce the most erosive, frequent and longest runout turbidity currents on deltas? Geophys. Res. Lett., 45, doi: 10.1002/2017GL075751.

Horner-Devine, A.R., Hetland, R.D. and MacDonald, D.G. (2015) Mixing and transport in coastal river plumes. Annu. Rev. Fluid Mech., 47, 569 - 594.

Houk, D. and Green, T. (1973) Descent rates of suspension fingers. Deep Sea Res., 20, 757 761.

Hoyal, D.C.J.D., Bursik, M.I. and Atkinson, J.F. (1999a) The influence of diffusive convection on sedimentation from buoyant plumes. Mar. Geol., 159, $205-220$.

Hoyal, D.C.J.D., Bursik, M.I. and Atkinson, J.F. (1999b) Settling-driven convection: A mechanism of sedimentation from stratified fluids. J. Geophys. Res., 104 (C4), 7953 - 7966, doi: 10.1029/1998JC900065.

Huppert, H.E. (2006) Gravity currents: a personal perspective. J. Fluid Mech., 554, 299 - 322.

Hughes Clarke, J.E., Marques, C.R.V. and Pratomo, D. (2014) Imaging active mass-wasting and sediment flows on a fjord delta, Squamish, British Columbia. In Submarine Mass Movements and Their Consequences, 249 - 260, Springer. divergent sediment plume. Cont. Shelf Res., 20 (16), 2239 - 2266.

44 
$63(5), 1041-1064$.

Manzella, I., Bonadonna, C., Phillips, J.C. and Monnard, H. (2015) The role of gravitational instabilities in deposition of volcanic ash. Geology, 43 (3), $211-214$.

Martin, D. and Nokes, R. (1998) Crystal settling in a vigorously convecting magma chamber. Nature, 332,534 - 536 .

Maxworthy, T. (1999) The dynamics of sedimenting surface gravity currents. J. Fluid Mech., 392, $27-44$.

Meiburg, E. and Kneller, B.C. (2010) Turbidity currents and their deposits. Annu. Rev. Fluid Mech., 42, 135 - 156.

Mulder, T. and Chapron, E. (2011) Flood deposits in continental and marine environments: character and significance. In Sediment Transport from Shelf to Deep Water - Revisiting the Delivery System, AAPG Stud. Geol., vol. 61, edited by R. M. Slatt and C. Zavala, pp. 1 - 30.

Mulder, T. and Syvitski, J.P.M. (1995) Turbidity currents generated at river mouths during exceptional discharges to the world oceans. J. Geol., 103 (3), 285 - 299.

Nowacki, D.J., Horner-Devine, A.R., Nash, J.D. and Jay, D.A. (2012) Rapid sediment removal from the Columbia River plume nearfield. Cont. Shelf Res. 35, 16-28.

Parsons, J.D. and Garcia, M.H. (2000) Enhanced sediment scavenging due to double-diffusive convection. J. Sediment. Res., 70 (1), $47-52$.

Parsons, J.D., Bush, J.W.M. and Syvitski, J.P.M. (2001) Hyperpycnal plume formation from riverine outflows with small sediment concentrations. Sedimentology, 48 (2), $465-478$.

Penney, J. and Stastna, M. (2016) Direct numerical simulation of double-diffusive gravity currents. Physics of Fluids 28, 086602; doi: 10.1063/1.4961045.

Rouhnia, M. and Strom, K. (2015) Sedimentation from flocculated suspensions in the presence of settling-driven gravitational interface instabilities. J. Geophys. Res. Oceans, 120, 6384 - 6404, doi: 10.1002/2015JC010750.

Rouhnia, M. and Strom, K. (2017) Sedimentation from buoyant muddy plumes in the presence of interface mixing: an experimental study. J. Geophys. Res. Oceans, 120, 2652 - 2670, doi: $10.1002 / 2016$ JC012053.

Shao, Y.C., Hung, C.Y. and Chou, Y.J. (2017) Numerical study of convective sedimentation through a sharp density interface. J. Fluid Mech., 824, 513 - 549.

Scheu, K.R., Fong, D.A., Monismith, S.G. and Fringer, O.B. (2015) Sediment transport 46 dynamics near a river inflow in a large alpine lake. Limnol. Oceanogr., 60 (4), 1195 - 1211. 
Simpson, J.E. (1982) Gravity currents in the laboratory, atmosphere and ocean. Ann. Rev. Fluid Mech., 14 (1), 213 - 234.

Snow, K. and Sutherland, B.R. (2014) Particle-laden flow down a slope in uniform stratification. J. Fluid Mech., 755, 251 - 273.

Scollo, S., Bonadonna, C., and Manzella, I. (2017) Settling-driven gravitational instabilities associated with volcanic clouds: new insights from experimental investigations. Bulletin of Volcanology, 79:39. https://doi.org/10.1007/s00445-017-1124-x.

Sparks, R.S.J., Carey, S.N. and Sigurdsson, H. (1991). Sedimentation from gravity currents generated by turbulent plumes. Sedimentology, 38 (5), 839 - 856.

Stack, K. M., Grotzinger, J. P., Lamb, M. P., Gupta, S., Rubin, D. M., Kah, L. C., Edgar, L. A., Fey, D. M., Hurowitz, J. A., McBride, M., Rivera-Hernández, F., Sumner, D. Y., Van Beek, J. K., Williams, R. M. E., and Yingst, R. A. (2018) Evidence for plunging river plume deposits in the Pahrump Hills member of the Murray formation, Gale crater, Mars. Sedimentology, doi: 10.1111/sed.12558

Sutherland, B.R., Gingras, M.K., Knudson, C., Steverango, L. and Surma, C. (2018) Particle-bearing currents in uniform density and two-layer fluids. Phy. Rev. Fluids, 3 (2), p.023801.

Talling, P. J., Paull, C.K. and Piper, D.J.W. (2013) How are subaqueous sediment density flows triggered, what is their internal structure and how does it evolve? Direct observations from monitoring of active flows. Earth-Sci. Rev., 112, 244 - 288.

Turner, J. S. (1979) Buoyancy Effects in Fluids. Cambridge University Press.

Warrick, J. A., Xu, J., Marlene, A. N. and Homa, J. L. (2008) Rapid formation of hyperpycnal sediment gravity currents offshore of a semi-arid California river. Cont. Shelf Res., 28, 991 1009 .

Yuan, Y. and Horner-Devine, A.R. (2017) Experimental investigation of large-scale vortices in a freely spreading gravity current. Phys. Fluids, 29(10), p.106603. https://doi.org/10.1063/1.5006176.

Yu, X., Hsu, T. J. and Balachandar, S. (2013) Convective instability in sedimentation: Linear stability analysis. J. Geophys. Res. Oceans, 118, 256 - 272, doi:10.1029/2012JC008255.

Yu, X., Hsu, T. J. and Balachandar, S. (2014) Convective instability in sedimentation: 3-D numerical study. J. Geophys. Res. Oceans, 119, 8141 - 8161, doi:10.1002/2014JC010123.

Zhixin, Q., Eames, I. and Greig, A. (2014) Flushing ballast tanks. Ocean Eng., 89, 157 - 172. 


\title{
Dynamics of settling-driven convection beneath a sediment-laden buoyant overflow: implications for the length-scale of deposition in lakes and the coastal ocean
}

\author{
Shahrzad Davarpanah Jazi and Mathew G. Wells \\ Department of Physical \& Environmental Sciences, University of Toronto \\ 1065 Military Trail, M1C 1A4, Toronto, ON, Canada \\ Email: sh.davarpanahjazi@mail.utoronto.ca, Email: wells@utsc.utoronto.ca
}

\begin{abstract}
A series of laboratory experiments were conducted in order to determine how settling-driven convection influences the length-scale over which the majority of particles settle beneath a buoyant sediment-laden plume spreading over a denser saline layer. This system is analogous to sediment-laden river water spreading into a lake or the coastal ocean. The key dimensionless parameter that controls the settling dynamics of such flows is the density ratio, defined as the ratio of density differences due to the added salt and sediment. For a buoyant plume, this ratio has to be greater than unity, so that the experiments in the current study were performed for density ratios between one and five. When density ratio was close to one, settling-driven convection was vigorous and the length-scale over which sedimentation occurred was very small. A strong secondary turbidity current was generated in this case. On the other hand, for larger values of density ratio, the predicted length-scale over which a secondary plume was generated increased proportional with the density ratio. A complete mathematical expression for this length-scale was developed using recent theory that described the time-scale over which settling-driven convection evolved. The theoretically predicted propagation length-scale showed very good quantitative agreement with laboratory experiments. The use of the dimensionless density ratio allows the expression to predict which sediment-laden river plumes in lakes and the coastal ocean could quickly form secondary turbidity currents.
\end{abstract}

Keywords: Sediment-laden gravity current, settling-driven convection, turbidity currents, density ratio, Stokes settling velocity, overflow. 


\section{INTRODUCTION}

Rivers are the main pathways by which sediment is transported to the coastal regions of lakes and the ocean (Mulder \& Syvitski, 1995). In a lake, a sediment-laden river is often denser than the receiving waters and so can readily plunge and form a turbidity current, as originally observed in pioneering work by Forel (1885) in Lake Geneva. In contrast, when a river flows into the coastal ocean, the buoyant density difference between the fresh and saline water is usually far greater than the unstable density difference due to the suspended sediment load. Hence, almost all sediment-laden rivers will form surface plumes in the coastal ocean (Mulder \& Syvitski, 1995). The processes that control the length-scale over which sediment deposits beneath these buoyant sediment-laden plumes is thus a key geological question. This lengthscale of deposition is directly related to the length-scale that the buoyant plume propagates before losing all its sediment from beneath. Such length-scale has been described as the product of the horizontal velocity of the buoyant plume and a time-scale over which sediment is lost (Geyer et al., 2004; Hill et al., 2000). The horizontal velocities velocity of a surface plume is well understood (Yuan \& Horner-Devine, 2017), and in the absence of strong winds or tides, it is largely determined by buoyancy forces (Horner-Devine at et al., 2015). The time-scale over which sedimentation occurs has been the focus of recent work by Hoyal et al. (1999b), Burns \& Meiburg $(2012,2015)$ and Davarpanah Jazi \& Wells (2016), who identified settling-driven convection as the potentially dominant fluid dynamical process that can rapidly transport sediment from beneath sediment-laden buoyant plumes. Previous experiments on buoyant surface sediment-1aden plumes (Maxworthy, 1999; Parsons et al., 2001; Snow \& Sutherland, 2014; Sutherland et al., 2018) and direct observations of buoyant surface sediment-laden plumes (Hughes Clarke et al., 2014; Hizzett et al., 2017) have shown showed that under certain conditions, the rapid sediment loss beneath such plumes can generate a secondary turbidity current, which could provide an important mechanism to transport sediment to the depths of the ocean from the continental margin. For instance, direct field monitoring by Clare et al. (2016) has revealed that $70 \%$ of observations of the triggering of secondary turbidity currents were linked to the sediment-laden plume in Howe Sound near the Squamish River in BC, Canada.

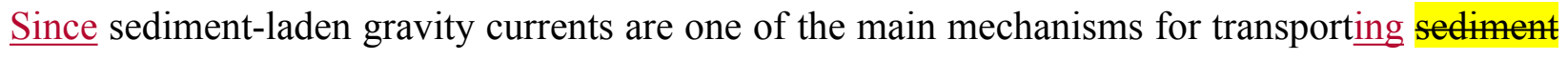
sediments into the deep ocean, where deep sand layers can form (Meiburg \& Kneller, 2010), this 
study aims to use laboratory experiments to quantify the conditions that can enhance sedimentation beneath such buoyant river plumes. Particularly, this study identifies the specific conditions that could potentially result in the formation of secondary turbidity currents from the many rivers in the coastal ocean that usually have low sediment loads and would almost always form surface plumes rather than plunging hyperpyenal underflows (Mulder \& Syvitski, 1995).

The length-scale over which a surface plume propagates and loses sediment will give a firstorder estimate of the distribution of sediment deposition from a river mouth, as illustrated schematically in Figure 1. If there are no currents beneath the surface plume, then the distance at which all of the sediment has fallen out of the plume determines the zone of deposition. If the concentrations are high enough, this depositing sediment could also potentially form a secondary turbidity current. Intuitively, the extent of propagation over which sediment is lost $\left(L_{\text {prop }}\right)$ can be approximated with equation (1) as follows:

$$
L_{\text {prop }}=U T_{S}=U\left(\underline{\bar{H}} / \underline{w_{S}}\right)
$$

where $\underline{U}$ is the horizontal velocity of the buoyant plume and $T_{S}$ is the time-scale over which particles settle through the moving surface plume. If particles are only being lost by a slow

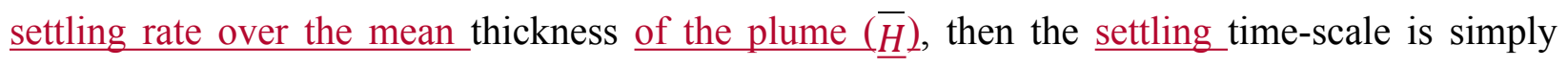
determined as $T_{S}=\underline{\bar{H}} / \underline{w}_{\underline{S}}$, where $\underline{w}_{\underline{S}}$ is the Stokes settling velocity of the sediment particles (Geyer et al., 2004; Hill et al., 2000). The horizontal velocity of a buoyant plume $(U)$ is a function of the reduced gravity $\left(g^{\prime}\right)$ between the plume and ambient and the thickness at the plume head $(H)$. Thus, this velocity is given by $U=\operatorname{Fr}\left(g^{\prime} H\right)^{1 / 2}$, where the reduced gravity is defined as $g^{\prime}=g \Delta \rho / \rho$, with $g$ the gravitational acceleration $\left(9.81 \mathrm{~m} \mathrm{~s}^{-2}\right)$ and $\Delta \rho$ and $\rho$ are respectively the density difference and average density between the current and the saline ambient with units of $\mathrm{kg} \mathrm{m}^{-3}$. The Froude number is the key dimensionless parameter for describing gravity current dynamics and is defined as $\mathrm{Fr}=U /\left(g^{\prime} H\right)^{1 / 2}$. Essentially the Froude number compares the observed speed to that of an internal wave speed. Numerous experimental studies have consistently found the Froude number to be order one (i.e. Turner, 1979; Simpson, 1982; Gladstone \& Pritchard, 2010; Snow \& Sutherland, 2014), which is close to the value of 1 / $\sqrt{2}$ found in theoretical studies (Benjamin, 1968; Huppert, 2006; Meiburg \& Kneller, 2010). 
Recent direct numerical simulations of buoyant double-diffusive gravity currents by Penney \& Stastna (2016) have suggested that a no-slip condition (representing a solid lid) may increase drag compared to a free-slip condition (representing an air-water interface), and hence they would predict different Fr than for buoyant plumes compared to regular bottom gravity currents.

Using typical values for tab laboratory and field situations, Equation (1) predicts very large propagation length-scales if the only settling process considered is Stokes settling velocity. For instance a typical gravity current in a lab laboratory experiment with a strong buoyancy difference, has a speed of order $U \sim 0.1 \mathrm{~m} \mathrm{~s}^{-1}$. The mean thickness of a typical laboratory gravity current is of order $\underline{\bar{H}}=0.1 \mathrm{~m}$. Hence, using for example Silicon Carbide $(\mathrm{SiC})$ sediment particles of size $7.8 \times 10^{-6} \mathrm{~m}$ with Stokes settling velocity of $\underline{w}_{S}=7.7 \times 10^{-5} \mathrm{~m} \mathrm{~s}^{-1}$, implies a settling time of $T_{S}=1300 \mathrm{~s}$. Therefore, assuming that the current is moving at $0.1 \mathrm{~m} \mathrm{~s}^{-1}$, it would need to propagate the very large distance of $130 \mathrm{~m}$ for all the particles to settle out of the plume, and hence laboratory plumes with fine sediment might be predicted to propagate to the end of any realistic experimental tank before losing all of their sediment. In contrast, previous laboratory experiments have found that settling-driven convection is much more important than just the $\underline{\text { Stokes settling velocity, so that laboratory plumes with fine sediment particles can lose sediment }}$ at much faster rates (Maxworthy, 1999; Parsons et al., 2001; Snow \& Sutherland, 2014, Sutherland et al., 2018). The scaling in Equation (1) assumes that within the gravity current particles are settling in a laminar fashion manner within the gravity current. If the flow is turbulent however, so that the concentration is well mixed, then the average mass concentration ( $\underline{C}$ with units of $\left.\mathrm{kg} \mathrm{m}^{-3}\right)$ in the flow changes with time as $C(t)=C_{o} e^{\left(-t W_{s} / \bar{H}\right)}$ (Martin \& Nokes, 1988; Sparks et al., 1991), where $C_{0}$ is the initial mass concentration of the flow $\left(\mathrm{kg} \mathrm{m}^{-3}\right)$. With

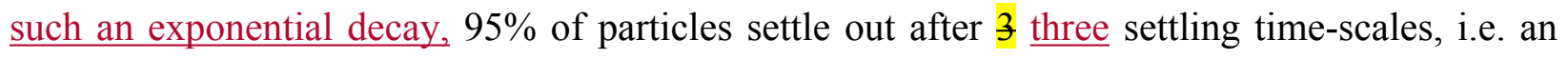
even greater distance is implied by Equation (1).

There are a number of mechanisms by which the time-scale used in Equation (1) could be much smaller than that predicted from the Stokes settling velocity of a single particle, including flocculation_(Rouhnia \& Strom, 2015, 2017) and settling-driven convection (Burns \& Meiburg, 2012, 2015). This study will focus on the potential role of settling-driven convection, as the description of increased settling rates due to flocculation is now quite mature (Rouhnia \& Strom, 
2015, 2017). Several field observations have found that sediment is lost from a buoyant plume at

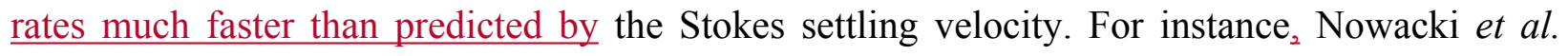
(2012) computed the sediment removal rate from the Colombia River, USA and determined that the settling rate $\left(10 \mathrm{~mm} \mathrm{~s}^{-1}\right)$ was substantially larger than the settling velocity of a single particle $\left(2 \mathrm{~mm} \mathrm{~s}^{-1}\right)$. Similarly, Scheu et al., (2015) used acoustic backscatter measurements beneath a river plume in a thermally stratified lake, to infer increases of an order of magnitude over the Stokes settling velocities of the suspended sediments settling from turbid river plumes. In the absence of flocculation, the most likely potential mechanism for these increased sedimentation rates is settling-driven convection, the vigour of which depends upon the unstable sediment contrast between the layers.

Settling-driven convection is an important instability that can occur when a layer of fresh sediment-laden water lies above a layer of saline water (Fig. 2). Initially this configuration can be stable if the mean density of the upper layer is less than that of the lower layer (as shown in Figure 2A). However, as sediment settles through the saline interface, a layer of particle rich fluid forms that contains both salt and sediment, and is now denser than the fluid below (the nose region in Figure 2B). Since this layer is unstable, convection of sediment-laden plumes begins (Fig. 2C). These dense sediment-laden finger-like plumes sink with vertical velocities that are 10 to 100 times larger than Stokes settling velocity (Hoyal et al., 1999b; Burns \& Meiburg, 2012, 2015; Davarpanah Jazi \& Wells, 2016). This process is highly important to Equation (1), as it $\underline{\text { suggests that a much shorter time-scale } T_{\underline{S}} \text { is relevant for sediment-laden buoyant plumes, so that }}$ the deposition length-scale will be far less than predicted by only assuming Stokes settling velocity of a single particle. Such finger-like plumes have been seen in a number of studies (Bradly, 1965; Hoyal et al., 1999b) and this process is seen to greatly increase the particle removal rate from an otherwise buoyant upper layer (Houk \& Green, 1973; Green, 1987; Chen, 1997; Hoyal et al., 1999a, b; Maxworthy, 1999; Parsons \& Garcia, 2000; Parsons et al., 2001; Davarpanah Jazi \& Wells, 2016). Recent work by Davarpanah Jazi \& Wells (2016) found showed that in a salt/sediment configuration with no horizontal velocities, the vigour of convection was dictated by density ratio defined as $R_{\rho}=\Delta \rho_{S} / \Delta \rho_{C}$, the ratio of density differences due to the added salt $\left(\Delta \rho_{\underline{S}}\right)$ and sediment $\left(\Delta \rho_{\underline{C}}\right)$. For a sediment-laden layer of fresh water to float above a saline layer, $R_{\rho}$ must be greater than one. The most vigorous convection 
was found to occur for marginal stability when $R_{\rho}$ was very close to one. Theoretical and numerical descriptions studies of settling-driven convection (Burns \& Meiburg, 2012, 2015; Yu et al., 2013, 2014; Shao et al., 2017) have quantified the time-scales for these processes, and revealed the internal dynamics of the velocity fields that are difficult to see experimentally.

One of the key findings of the previous experiments and field observations on buoyant sediment-laden plumes is that settling-driven convection is an important mechanism for moving sediments rapidly from surface plumes to the lake or ocean bed, where dense secondary turbidity currents can potentially form (Maxworthy, 1999; Parsons et al., 2001; Snow \& Sutherland, 2014; Hughes Clarke et al., 2014; Sutherland et al., 2018). As almost all sediment-laden river plumes are initially buoyant, over a hundred many papers have cited Parsons et al. (2001) to suggest settling-driven convection could be a key process by which turbidity currents can be formed in the coastal ocean near river mouths, which ultimately transport sediment to deep regions of the ocean (Meiburg \& Kneller, 2010). It is very challenging in a field study to isolate the specific mechanism by which secondary turbidity currents can be generated from a buoyant sedimentladen plume (Gales et al., 2018), and only a limited number of field studies have attempted to investigate this process (see for example optical backscatter measurements of Hughes Clarke et al. 2014, Kineke et al. 2000 and Hill et al. 2008). This has placed great importance to these earlier experiments, especially Parsons et al. (2001). In the current study, the aim is to revisit these earlier experiments, and improve the understanding on processes that set the length-scale in Equation (1) in light of the recent improvements to the theoretical understanding of the timescales of settling-driven convection (Burns \& Meiburg, 2012, 2015; Yu et al., 2013, 2014; Shao et al., 2017). Specifically, this paper aims to extend the initial study of Maxworthy (1999) by applying the time-scale used in Burns \& Meiburg $(2012,2015)$ to determine how the lengthscale in Equation (1) varies as a function of density ratio $\left(R_{\rho}\right)$.

The experiments in this paper aim to quantify how settling-driven convection could control the length-scale of deposition beneath a buoyant plume, and isolate the specific conditions under which secondary turbidity currents can form. As this process is challenging to study in the field, the presented experimental visualizations of such processes will help geologists to better conceptualize field observations. Using the most recent results from modelling of settling-driven 
convection, a new equation is developed to describe the distance over which sediment is lost due to settling-driven convection. There is excellent agreement between the quantitative theory and the laboratory results. The paper ends with an extrapolation of the findings of this study to predict the relevant length-scales for river plumes entering the coastal ocean.

\section{EXPERIMENTAL DESIGN}

In order to better understand how the process of settling-driven convection controls deposition beneath buoyant plumes in lakes and the coastal ocean, a series of experiments were performed, where a controlled volume of sediment-laden fluid was released into a large tank that contained a well-mixed saline solution (Fig. 3). The large tank had dimensions of $1.83 \times 0.55 \times 0.305 \mathrm{~m}$, and sediment-laden fluid was initially contained behind a removable metal barrier in a compartment of dimensions $0.35 \times 0.115 \times 0.23 \mathrm{~m}$. The two compartments were the same temperature, as they were both filled with tap water stored in large vessels that had equilibrated with room temperature $\left(18.5 \pm 2.3^{\circ} \mathrm{C}\right)$. Keeping the temperature constant throughout all experiments, resulted in a two-component salt/sediment configuration similar to experiments of Maxworthy (1999). The ambient saline solution was prepared from high purity food grade salt. The sediment used in the experiments was Silicon Carbide ( $\mathrm{SiC}$ ) grinding powder with a density of $\rho_{S i C}=3210$ $\mathrm{kg} \mathrm{m} \mathrm{m}^{-3}$. This material is monodispersed and non-cohesive and was previously used in the experiments of Maxworthy (1999), Hoyal et al. (1999b), Davarpanah Jazi \& Wells (2016) and Sutherland et al. 2018. The median diameter of particles was $7.8 \times 10^{-6} \mathrm{~m}$, resulting in a predicted Stokes settling velocity of $7.7 \times 10^{-5} \mathrm{~m} \mathrm{~s}^{-1}$.

In these experiments, the salinity contrast between the surface plume and the ambient fluid was kept constant, and the sediment concentration was increased. Thus, the density ratios varied from $R_{\underline{\rho}}=\infty$ (no sediment) to $R_{\underline{\rho}}=1$ (neutral stability). The cases where $R_{\underline{\varrho}}<1$ would have the sediment being denser than the ambient fluid so would immediately form underflows. The density of the saline ambient $\left(\rho_{S}\right)$ was kept constant at $1002.5 \pm 0.4 \mathrm{~kg} / \mathrm{m}^{3}$, while the amount of sediment added to surface plume was varied. The different densities of sediment-laden water $\left(\rho_{C}\right)$ were obtained by adding various masses of sediment $\left(0 \leq m_{C} \leq 0.065 \mathrm{~kg}\right)$ to the fixed volume of fresh water within the small compartment. The mass of sediment was determined using an Ohaus 
SPX222 balance (Ohaus Corporation, Parsippany, NJ, USA) with precision of $10^{-2} \mathrm{~g}$. The densities of saline water $\left(\rho_{S}\right)$ and the water in the compartment, before adding sediment $\left(\rho_{\text {comp }}\right)$, were measured using an Anton Paar DMA 35 Ex portable densitometer (Anton Paar USA Inc., Ashland, VA, USA) with an accuracy of $\pm 10^{-3} \mathrm{~g} \mathrm{~cm}^{-3}$ and a resolution to $10^{-4} \mathrm{~g} \mathrm{~cm}^{-3}$. The temperatures $\left(t_{S}\right.$ and $t_{\text {comp }}$ ) were measured simultaneously with the same instrument to the precision of $0.2^{\circ} \mathrm{C}$.

The density of a fluid can be determined as $\rho_{f}=\rho_{0}+\Delta \rho_{S}+\Delta \rho_{C}$ and is linearly related to both concentrations of salt and sediment. Here, $\rho_{0}$ is the density of clear fresh water at $20^{\circ} \mathrm{C}(998.2 \mathrm{~kg}$ $\mathrm{m}^{-3}$ ). The added density due to the added salt was calculated using $\Delta \rho_{S}=\rho_{S}-\rho_{\text {comp }}$, where the density of fresh water in the compartment is $\rho_{\text {comp }}=999.1 \pm 0.2 \mathrm{~kg} \mathrm{~m}^{-3}$. The density anomaly due to the added sediment was calculated as $\Delta \rho_{C}=\gamma C \rho_{\text {comp }}$, in which $\gamma$ is the density expansion coefficient for $\mathrm{SiC}$ particles defined as $\left(\rho_{S i C}-\rho_{\text {comp }}\right) / \rho_{S i C}$. Furthermore, $\varphi$ is the mass concentration of sediment particles $\left(\mathrm{kg} \mathrm{kg}^{-1}\right)$ denoted by $\varphi=m_{C} /\left(m_{C}+m_{\text {comp }}\right)$, where the mass of the water in the small compartment $\left(m_{\text {comp }}\right)$ was determined as $m_{\text {comp }}=\rho_{\text {comp }} V_{\text {comp }}$, in which $V_{\text {comp }}$ was the volume of the compartment $\left(\mathrm{m}^{3}\right)$.

The entire tank was initially filled with saline water with density $\rho_{S}$, and then the barrier was inserted to isolate the smaller compartment. With the use of two small pumps, the saline water in this compartment was replaced with freshwater, by discharging salt water out and pumping fresh water in simultaneously. An equivalent of four times the volume of the small compartment was replaced in order to guarantee that $99 \%$ of the saline water was flushed out (Zhixin et al., 2014). An electrical mixer was used to keep the fluid well-mixed while being replaced.

The sediment particles were then added to the fresh water in the small compartment and a well-mixed constant volume of sediment-laden water was prepared. The electrical mixer kept the fluid stirred to inhibit the settling of particles and the total time between addition of sediment and removal of barrier was kept to less than two minutes. Each experiment commenced with the gentle removal of the metal barrier $10 \mathrm{~s}$ after the mixer was turned off to prevent turbulent motion it produced within the fluid. In addition, food dye was added to the sediment water to further improve flow detection. Digital cameras were used to capture the behaviour of the flow 
from different angles through photos and movies. Two large LED light panels provided bright and uniform lighting at the background in order to produce clear, sharp photos and movies from the sediment-laden gravity current in motion.

A total of 19 experiments with density ratios in the range of $0.687 \leq R_{\rho} \leq \infty$ were performed. Full details of all 19 experiments, including $R_{\rho}, m_{C}, L_{\text {prop }}$ and the behaviour of sediment-laden overflows, are summarized in Table 1. The six supplemental movies are available online and are representative of the major trends in the behaviour of the current. In this table the experiments are in an ascending order based on their density ratio. The experiment with $R_{\rho}=\infty$ (Movie S6 in the Supplemental section) had no sediment, and the one experiment with $R_{\rho}=0.687$ (Movie S1 in the Supplemental section) had sediment load such that it was initially denser than saline ambient; all the other 17 experiments were initially positively buoyant and were in the range $1.021 \leq R_{\rho} \leq 4.575$. The above two experiments $\left(R_{\rho}=\infty\right.$ and 0.687$)$ were performed only for comparison purposes, as the main focus of this study was on particle-laden sediment-laden overflows. The propagation length-scale of the gravity current $\left(L_{p r o p}\right)$ was measured by visually determining the distance at which the thickness of the gravity current became less than $0.01 \mathrm{~m}$ and had essentially stopped. The error bars in the determinations of $L_{p r o p}$ represent an estimate of the distance over which the gravity current changes from $0.02 \mathrm{~m}$ to $0 \mathrm{~m}$ thickness.

\section{THEORY}

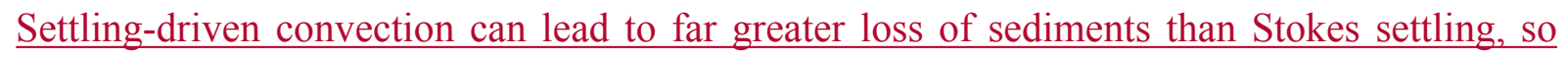
that use of Equation (1) would predict a much smaller and more realistic deposition length-scale. In this section, the scaling of $L_{\text {prop }}$ is now modified to take into account theoretical scaling of the sedimentation time-scale, introduced by Burns \& Meiburg $(2012,2015)$ to show how the density ratio $\left(R_{\rho}\right)$ and the stratification influence the propagation length-scale. In order to use Equation (1) a horizontal velocity $(U)$ and a sedimentation time-scale $\left(T_{S}\right)$ are needed. For the former, the horizontal velocity of the plume is a function of the reduced gravity, which can be expressed in terms of the contribution of sediment and salt density anomalies as,

$$
U=\operatorname{Fr}\left(\frac{g H}{\rho}\left(-\Delta \rho_{C}+\Delta \rho_{S}\right)\right)^{1 / 2}
$$


where $\Delta \rho_{S}$ and $\Delta \rho_{C}$ are the added density due to the added salt and mass fraction of sediment respectively. By introducing the definition of density ratio $\left(R_{\rho}=\Delta \rho_{S} / \Delta \rho_{C}\right)$ previously used by Davarpanah Jazi \& Wells (2016), this velocity can be rewritten in terms of density ratio $\left(R_{\rho}\right)$ and Froude number (Fr) as,

$$
U=\operatorname{Fr}\left(\frac{g \Delta \rho_{S}}{\rho} H\left(1-\frac{1}{R_{\rho}}\right)\right)^{1 / 2}
$$

The sedimentation time-scale $\left(T_{S}\right)$ is determined by the dynamics of the instability at the interface between sediment-laden and saline fluid (Burns \& Meiburg, 2015). The downward settling of sediment_particles from the fresher layer into the denser saline layer (Fig. 2A) drives the settling-driven convection instability. A very thin layer of fluid, just below the interface containing both salt and sediment, forms a "nose" of unstable stratification with length-scale $\left(\underline{L}_{C}\right)$, as shown in Figure 2B. The convective instability at the base of the sediment-laden fluid is controlled by this thin "nose" region, as there is an unstable density inversion due to accumulation of settling sediment from above (Burns \& Meiburg, 2012). When this layer grows sufficiently large, the dense material will sink as a convective plume (Fig. 2C). The numerical simulations of Burns \& Meiburg $(2012,2015)$ and Shao et al. (2017) have shown that within the

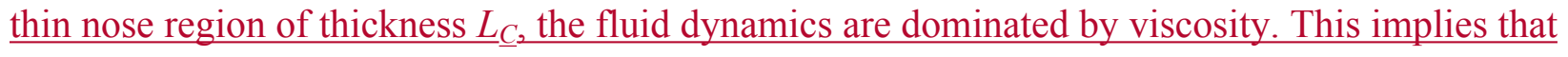
both Grashof number and Reynolds number are equal to one at the point just before instability occurs.

The Grashof number is defined as,

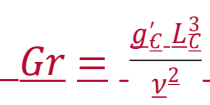

where $g_{C}^{\prime}=g \Delta \rho_{C} / \rho_{0}$ is the reduced gravity defined in terms of the density difference due to the added sediment $\left(\Delta \rho_{C}\right)$ and density of fresh water $\left(\rho_{0}\right)$ (Burns $\&$ Meiburg, 2012, 2015) and $v=10^{-}$ ${ }^{6} \mathrm{~m}^{2} \mathrm{~s}^{-1}$ is the coefficient of kinematic viscosity of fresh water at $20^{\circ} \mathrm{C}$. In this region, a Reynolds number can also be defined as, 


$$
\operatorname{Re}=\frac{w_{s} L_{C}}{v}
$$

where the vertical velocity of fluid in this layer is assumed to be the same as the settling velocity $\underline{w_{s}}$ (Shao et al., 2017).

The important time-scale for convective instability can be derived through the following steps. First, assuming $\mathrm{Re}=1$ implies that

$$
\underline{L} \underline{\underline{C}} \equiv \frac{\underline{v}}{-\underline{w_{S}}}
$$

Similarly assuming that in the viscosity dominated unstable nose region $\mathrm{Gr}=1$ results in a scaling for the thickness of the nose region in terms of the viscosity and reduced gravity as,

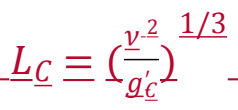

Note that $g_{C}^{\prime}$ is the reduced gravity defined in terms of the density difference due to the added sediment $\left(\Delta \underline{\rho}_{C}\right)$ and density of fresh water $\left(\underline{\rho}_{0}\right)$. By equating Equations $(6)$ and $(7)$, the settling velocity within the convectively unstable nose region is shown to be related to the reduced gravity of the sediment layer and viscosity as,

$$
\underline{w}_{\underline{S}}=\left(g_{\underline{\underline{C}}} \underline{v}\right)^{\underline{1 / 3}}
$$

(8)

Therefore using Equation (6), the time-scale $\left(T_{C}=L_{C} / w_{\underline{S}}\right)$ for a particle of velocity $w_{\underline{S}}$ to fall into the unstable nose region of thickness $L_{C}$ would be given by,

$$
T_{\underline{C}}=\left(\frac{v}{g^{\prime} c^{2}}\right)^{1 / 3}
$$


Note that this expression does not contain the Stokes settling velocity $\left(w_{S}\right)$. This resulting time$\left.\underline{\text { scale }(} T_{C}\right)$, is the fundamental time-scale for the convective sedimentary instability, and has been used in a number of important recent studies to non-dimensionalize the time-scales of various numerical simulations (Burns \& Meiburg 2012, 2015; Shao et al., 2017). Their resulting 3D simulations suggest that it takes of order 100 time-scales for fully developed settling-driven convection to develop. This convective time-scale will subsequently be used in this paper to determine the experimental length-scale over which sediment is lost from the bottom of a surface plume. From this point onwards, $c_{t}$ will be defined as the dimensionless multiple of the time in Equation (9) that takes for settling-driven convection to develop, and the value of $\underline{c}_{t}$ will be determined experimentally. It will be assumed that the sedimentary convective time-scale of Burns \& Meiburg $(2012,2015)$ is the relevant time-scale for sediment to be lost from the sharp density interface beneath the overflow so that $T_{\underline{S}}=T_{C}$. With this assumption, Equations (3) and (9) can be combined to estimate a propagation length-scale $\left(L_{\text {prop }}\right)$ for the gravity current as,

$$
L_{\text {prop }} \sim \operatorname{Fr}\left(g \frac{\Delta \rho_{S}}{\rho_{0}} H\left(1-\frac{1}{R_{\rho}}\right)\right)^{1 / 2} v^{1 / 3}\left(g \frac{\Delta \rho_{C}}{\rho_{0}}\right)^{-2 / 3}
$$

To see the dependence on $R_{\rho}$ even more clearly, by keeping the salinity anomaly $\Delta \rho_{S}$ constant and assuming $\mathrm{Fr} \sim 1$, then two dimensional constants are introduced, $c_{1}=\left(g \Delta \rho_{S} H / \rho_{0}\right)^{1 / 2}$ and $c_{2}$ $=v^{1 / 3}\left(g \Delta \rho_{S} / \rho_{0}\right)^{-2 / 3}$, with units of $\mathrm{m} \mathrm{s}^{-1}$ (speed) and $\mathrm{s}$ (time) respectively. This reduces the propagation length-scale to a simple function of $R_{\rho}$ as,

$$
L_{\text {prop }}=c_{1} c_{2} c_{t}\left(1-\frac{1}{R_{\rho}}\right)^{1 / 2} R_{\rho}^{3 \cdot / 3}
$$

where the combined coefficients $c_{1} c_{2}$ (assuming $\rho \approx \rho_{0}$ ) can be furthermore simplified to provide a scale constant (with units of $\mathrm{m}$ ) as,

$$
c_{1} c_{2}=H^{1 / 2} v^{1 / 3}\left(g \frac{\Delta \rho_{S}}{\rho}\right)^{-1 / 6}
$$

The propagation length-scale $\left(L_{\text {prop }}\right)$ in Equation (11) goes to zero as $R_{\rho}$ approaches unity (when there is no density difference between the two layers) and it increases as $R_{\rho}^{2 / 3}$ for large $R_{\rho}$. For 
the case of $R_{\rho}<1$ an underflow would occur as the plume would be initially denser than the receiving environment.

\section{RESULTS}

\section{Evolution of the current is related to density ratio}

The striking differences in the behaviour of the sediment-laden current can be seen in the photograph time series from experiments (Figs. 4, 5 and 6). In particular, the propagation lengthscale of the plume is a strong function of the density ratio and decreases as $R_{\rho}$ gets close to one. $\underline{\text { Secondary turbidity currents are also seen to form most strongly as } R_{Q} \text { gets close to unity. In all }}$ cases, the changes in behaviour are tied to the vigour of settling-driven convection that strongly increases as $R_{\rho}$ decreases towards unity.

The speed at which sediment-laden plumes sink beneath the surface plume increases dramatically with decreasing $R_{\rho}$ (Fig. 4). The series of photographs in Figure 4 depicts the behaviour of the overflow every $30 \mathrm{~s}$ for $R_{\rho}=3.051$ and 1.48 (left and right panels respectively). The higher value $R_{\rho}=3.051$ in Figures $4 \mathrm{~A}$ to $4 \mathrm{~J}$ means there is less sediment, and results in weak settling-driven convection. On the other hand for a smaller density ratio of $R_{\rho}=1.48$, Figures $4 \mathrm{~K}$ to $4 \mathrm{~T}$ depicts a very vigorous mode of settling-driven convection, which resulted in the rapid sinking of distinct finger-like structures. Figures $4 \mathrm{~J}$ and $4 \mathrm{Q}$ display evidence of settling to the bottom after $270 \mathrm{~s}$ and $180 \mathrm{~s}$ respectively. These corresponds to vertical velocities of approximately $w=0.14 \times 10^{-3} \mathrm{~m} \mathrm{~s}^{-1}$ for $R_{\underline{L}}=3.051$, whereas for $R_{\underline{L}}=1.48$ the vertical velocity is faster with $w=2.2 \times 10^{-3} \mathrm{~m} \mathrm{~s}^{-1}$. For comparison, the Stokes settling velocity of an individual particle is $7.7 \times 10^{-5} \mathrm{~m} \mathrm{~s}^{-1}$, and hence the estimated time from the Stoke settling velocity for a single $\mathrm{SiC}$ particle to go from the top to the bottom of the experimental tank is $2 \mathrm{hr}$. Thus, Figure 4 shows that settling-driven convection at low density ratios has a substantial effect on increasing the downward velocity of collections of $\mathrm{SiC}$ particles.

The shapes of the sinking sediment-laden fingers also change with increasing density ratio as displayed in Figure 5. These close-up images illustrate the reduction in width and velocity of the convective sediment fingers as density ratio increases. Figure 5 displays zoomed in photos, taken 
every $30 \mathrm{~s}$, and shows weaker settling-driven convection for $R_{\rho}=4.575$ and a much more vigorous settling-driven convection for $R_{\rho}=1.229$. The vertical distance moved by fingers between images indicate faster velocities for $R_{\rho}=1.229$, where the fingers of sediment were wider and formed earlier (compared to $R_{\rho}=4.575$ ). The vertical velocity of the small plumes (for $\underline{R}_{\underline{L}}=4.575$ ) and the large fingers (for $R_{\rho}=1.229$ ) can be estimated as $\underline{w}=6 \times 10^{-4} \mathrm{~m} \mathrm{~s}^{-1}$ and $\underline{w}=$ $3 \times 10^{-3} \mathrm{~m} \mathrm{~s}^{-1}$ respectively (similar to Figure 4). A general trend in both Figures 4 and 5 is that as density ratio decreases towards unity, the surface current moved slower horizontally and the formation of finger-like structures occurred earlier. With the increase in the mass of particles for lower $R_{\rho}$, the sediment settled faster as well as entraining water out of the current (as described before by Maxworthy (1999) and Sutherland et al. (2018)). Therefore, the head of the current decreased in size and could eventually stop before the end of the tank if settling-driven convection was vigorous enough.

In many experiments, the intense settling-driven convection could form a turbid interflow or an intense turbidity current beneath the buoyant plume (Fig. 6). The series of photos in Figure 6, taken every $60 \mathrm{~s}$, displays these two distinct behaviours of flow for $R_{\rho}=1.172$ and $R_{\rho}=1.054$. In both cases the current moved visibly slower (in the horizontal direction) than those discussed earlier in Figure 5. As can be seen in Figure 6, both currents never reached the end of the tank and stopped before passing $1.5 \mathrm{~m}$, as the sediments settled rapidly due to the very vigorous settling-driven convection of $\mathrm{SiC}$ particles. In Figures $6 \mathrm{E}$ to $6 \mathrm{~J}$, corresponding to $R_{\rho}=1.172$, after the overflow stopped at $L_{\text {prop }}=1.3 \mathrm{~m}$, it was interesting to observe the emergence of an interflow below the initial overflow, which lasted for a long time. In this case not only the sediment particles were falling down but they were also dragging water down with them. However, these plumes were not heavy enough to plunge down to the very bottom of the tank. Therefore, the amount of water that the plume carried with itself became significant (similar observations are reported in Sutherland et al. 2018). On the other hand, for $R_{\rho}=1.054$ the overflow stopped at a shorter distance of $L_{\text {prop }}=0.75 \mathrm{~m}$ and an underflow occurred shortly after. This formation of a secondary underflow is consistent with observations first made by Maxworthy (1999).

\section{Horizontal propagation of the current is related to density ratio}


The difference between the horizontal velocities of the buoyant plumes with various density ratios can be determined from a series of horizontal photos of the top $0.127 \mathrm{~m}$ of the overflow (Fig.7). The standard equation for the velocity in a buoyant plume (Eq. 3) predicted that the horizontal velocity would scale with density ratio as $U \sim\left(1-1 / R_{\rho}\right)^{1 / 2}$, i.e. the velocity decreases as $R_{\rho}$ approaches one, where there is no density difference. Equation (3) is governed by the dimensionless Froude number, which has usually been found to be between 0.5 to 1 in many previous experiments (i.e. Turner, 1979; Simpson, 1982; Gladstone \& Pritchard, 2010; Snow \& Sutherland, 2014). As an illustration of this, three cases of $R_{\rho}=\infty, 2.492$ and 1.172 are considered here. The speed of the overflow was determined by fitting the best line to the front of the current in each stack of images. The speeds corresponding to the density ratios under consideration were $U_{(R \rho=\infty)}=0.0279 \mathrm{~m} \mathrm{~s}^{-1}, U_{(R \rho=2.492)}=0.0246 \mathrm{~m} \mathrm{~s}^{-1}$ and $U_{(R \rho=1.172)}=0.0068 \mathrm{~m}$ $\mathrm{s}^{-1}$. Note that for $R_{\rho}=1.172$ the gravity current stopped at $L_{\text {prop }}=1.3 \mathrm{~m}$, as was also displayed in Figure 6. The comparison of the initial speed of the propagating overflow in the three figures shows a faster speed for the larger density ratios, consistent with the scaling of Equation (3). Using the observed experimental speeds, Equation (3) then determines the Froude number for $R_{\rho}$ $=\infty$ to be $\operatorname{Fr}_{(R \rho=\infty)}=0.820$. Furthermore, estimations of the Froude number based on Equation (3) for $R_{\rho}=2.492$ and 1.172 are $\operatorname{Fr}_{(R \rho=2.492)}=0.880$ and $\operatorname{Fr}_{(R \rho=1.172)}=0.506$ respectively. These estimates of the dimensionless Froude numbers are all within the expected range of 0.5 to 1 from previous experiments (i.e. Turner, 1979; Simpson, 1982; Gladstone \& Pritchard, 2010). It is also noteworthy in Figure 7 that in all three cases there appears to be no influence from the end wall on these estimates of propagation speed, as the horizontal velocity is constant with time up to the point where plumes hit the wall.

There is very good quantitative agreement between the theoretical prediction of Equation (11) and experimental results of the propagation length-scale of the sediment-laden gravity current as a function of density ratio (Fig. 8). This is the most important result in this paper, and Figure 8 shows that the propagation length-scale decreases to zero as density ratio decreases to one. For $\underline{R}_{\underline{L}}$ less than one a plunging flow would occur. The data points are surrounded by two curves in blue, which provides upper and lower bounds on the constants $c_{1}$ and $c_{2}$ in Equation (12). For experimental conditions in the current study, where $2.9 \mathrm{~kg} \mathrm{~m}^{-3} \leq \Delta \rho_{S} \leq 3.7 \mathrm{~kg} \mathrm{~m}^{-3}$, the two constants are in the range of $0.0380 \leq c_{1} \leq 0.0619 \mathrm{~m} \mathrm{~s}^{-1}$ and $0.0967 \leq c_{2} \leq 0.1848 \mathrm{~s}$, so that the 
product of $c_{\text {lavg }} c_{2 a v g}=0.0069 \mathrm{~m}$. As outlined earlier, previous numerical simulations of Burns \& Meiburg $(2012$, 2015) suggest that it will take several hundred time-scales for large "finger" instabilities to develop, and so in Figure 8 the blue theoretical curves are plotted to have values of $c_{t}=\underline{440}$ and $\underline{500}$. These two values bracket the observations well and are consistent with the expectation that $c_{t}$ is of order 100 . For typical values of $c_{1}$ and $c_{2}$ in lab laboratory conditions, with $1<R_{\rho}<2$, the propagation length-scale is predicted to be $0<L_{\text {prop }} \leq 1.83 \mathrm{~m}$. Furthermore, for any $R_{\rho}>1.3$ in the conducted experiments the observed propagation length-scale $\left(L_{\text {prop }}\right)$ was limited to the tank length of $1.83 \mathrm{~m}$. It is important to note that all these observations have length-scales dramatically smaller than the prediction of $L_{\text {prop }}$ based on the Stokes particle settling rate in Equation (1). The much smaller length-scale is a direct result of the increase rate of particle loss under the influence of settling-driven convection process.

\section{DISCUSSION}

\section{Density ratio predicts the sedimentation pattern}

The fluid dynamics of the convective sedimentation beneath a buoyant river plume are strongly influenced by the density ratio, as summarized in Figure 9 . In the experiments with lower sediment concentrations $\left(R_{\rho}>2\right)$, weak settling-driven convection and slow sinking of particles (e.g. $w=6 \times 10^{-4} \mathrm{~m} \mathrm{~s}^{-1}$ ) were observed, in experiments that lasted for a long duration of time (e.g. $\mathrm{t}=45 \mathrm{~min})$. On the other hand, when $1.3<R_{\rho}<2$ fingers of sediment were rapidly sinking with much greater vertical velocities of $w=0.3 \times 10^{-3} \mathrm{~m} \mathrm{~s}^{-1}$ under the direct effect of strong and vigorous settling-driven convection. In both of the above-mentioned cases the current reached the end wall, so that $L_{\text {prop }}=1.83 \mathrm{~m}$ for these experiments in Figure 8 . For higher sediment concentrations with $1.17<R_{\rho}<1.23$, the surface plume stopped well before reaching the end wall. In these cases, a slow moving sediment-laden interflow occurred beneath the surface plume. Finally, for cases where $R_{\rho}$ was very close to unity not only the surface flow stopped, but also an intense underflow was observed. In a much longer tank, it is likely that all the flows would have stopped, and hence formed some sort of subsurface gravity current. However, it is noteworthy that the only intense secondary underflow occurred when $R_{\underline{\alpha}} \sim 1$. It is very challenging to interpret isolated field observations beneath a river plume. Hence, the images and animations of these various experiments (Supplementary material) when combined with 
field estimates of $R_{\rho}$ could provide a useful guidance for interpretation of data and the possible design of future field observation campaigns.

The most important results of the current set of experiments is that Equation (11) quantifies the length-scale over which it is likely that a surface sediment-laden plume can transform into a subsurface turbidity current (Fig. 10). In lakes with smaller lengths than $L_{\text {prop }}$ the sediment is expected to rain down uniformly over the lake bed, possibly with some size fractionation with larger particles closer to river mouth. However, if $L_{\text {prop }}$ is sufficiently small compared to the size of the lake, then a secondary turbidity current could form and deposit sediments far from the river mouth, which are often ponded in the deepest regions of the basin. These two forms of sedimentation will result in quite different stratigraphy in lakes' beds, which can then be used to infer paleoclimate records of inflow events (Gilbert \& Butler, 2004; Cossu et al., 2015).

The mechanism of transforming a buoyant sediment-laden plume into a secondary turbidity current was first expressed by Maxworthy (1999) and greatly popularized in the sedimentology literature by Parsons et al. (2001). This process is often invoked as a potential mechanism by which turbidity currents can form, given that typically sediment loads in rivers are not high enough to directly form hyperpyenal underflows (Mulder \& Syvitski, 1995; Mulder \& Chapron, 2011). Equation (11) can now be used to rigorously quantify when secondary turbidity currents are likely to form. The experimental observations and theoretical predictions in this study confirm that the propagation length-scale of such a flow can dramatically change once density ratio gets very close to unity and it scales as $L_{\text {prop }} \sim\left(1-1 / R_{Q}\right)^{1 / 2} R_{\underline{Q}} \underline{2 / 3}$. When $R_{\underline{Q}}$ is less than one, an underflow would form. It is expected that sediment-laden river inflows into lakes will typically have much lower density ratios than in the coastal ocean, so that the behaviour of sedimentation and deposition scales will be very different for the same sediment load in a river (Fig. 9). When a river flows into a lake, the density difference arises due to the temperature anomaly (rather than the salinity difference). The largest density anomaly expected in most lakes

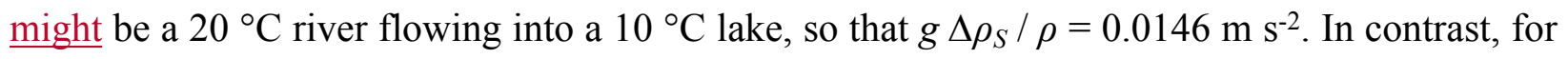
a fresh river entering the ocean saline water the reduced gravity would be of order $g \Delta \rho_{S} / \rho=$ $0.294 \mathrm{~m} \mathrm{~s}^{-2}$, i.e. at least 20 times greater. Thus, for the same sediment load, $R_{\rho}$ is always much larger than one in the ocean and much closer to one in a lake. Underflows are frequently 
observed in rivers entering lakes (see for example Fig.19D-2 in Talling et al. 2013, and Cossu et al. 2015), whereas only very rarely do rivers have enough sediment load in the ocean to form underflows (Mulder \& Syvitski, 1995; Mulder \& Chapron, 2011). As an example, $\underline{\text { Hughes }}$ Clarke et al. (2014) describe typical sediment concentrations as usually being less than $0.07 \mathrm{~kg}$ $\mathrm{m}^{-3}$ in the Squamish River. In the coastal ocean this is clearly insufficient to form an underflow directly, and the estimated density ratio would be $R_{\rho} \sim 25 \mathrm{~kg} \mathrm{~m}^{-3} / 0.07 \mathrm{~kg} \mathrm{~m}^{-3} \sim 350$. In contrast, if this same river flowed into a thermally stratified lake with a large $10{ }^{\circ} \mathrm{C}$ difference across the thermocline, it would have $R_{\rho} \sim 1.5 \mathrm{~kg} \mathrm{~m}^{-3} / 0.07 \mathrm{~kg} \mathrm{~m}^{-3} \sim 20$, and could potentially even have $R_{\rho} \sim 1$, if the temperature difference between river and lake was less than $1{ }^{\circ} \mathrm{C}$. For $R_{\rho}$ >> 1 then $L_{\text {prop }} \sim R_{\rho}^{2 / 3}$, so the difference in propagation length between $R_{\rho}=20$ and 350 is a factor of 100, indicating a substantial difference in the likely deposition behaviour between a lake and the ocean.

\section{From laboratory experiments to the field}

The idea from Parsons et al. (2001) that settling-driven convection can lead to formation of turbidity currents has been often invoked to explain field observations of turbidity currents, but only a few field studies detail some of the causal links. For instance, Hizzett et al. (2017) noted that the occurrence of turbidity current below the delta of the Squamish River correlated best with the presence of sediment-laden river plumes, rather than slope failures on the delta. In addition, Schue et al. (2015) studied a sediment-laden river plume flowing into a thermally stratified Alpine lake, and observed (using acoustic backscatter) that the vertical velocity of a descending sediment layer below a river plume was an order of magnitude greater than Stokes settling velocities, consistent with the experimental plumes in Figure 4. Furthermore, Giovanoli (1990) studied the transport of sediments from Rhône River flowing into Lake Geneva as an interflow. As mentioned in this study, the sediment concentration in the Rhône River is in the range of $10-5000 \mathrm{mg} \mathrm{l}^{-1}$. With the assumption that there is a $10{ }^{\circ} \mathrm{C}$ temperature difference between the two layers, it would result in a density ratio within the range of $0.3<R_{\rho}<150\left(R_{\rho} \sim\right.$ $1.5 \mathrm{~kg} \mathrm{~m}^{-3} / 5 \mathrm{~kg} \mathrm{~m}^{-3} \sim 0.3$ and $\left.R_{\rho} \sim 1.5 \mathrm{~kg} \mathrm{~m}^{-3} / 0.01 \mathrm{~kg} \mathrm{~m}^{-3} \sim 150\right)$. When $R_{\underline{\alpha}} \leq 1$ in Rhône River underflows would form, while for $1<R_{\underline{L}}<150$ there is the potential that settling-driven convection could be important underneath the Rhône River. 


\section{Application of experimental results to river flows into the coastal ocean}

$\underline{\text { Rivers only occasionally have sufficient suspended sediment to have a density that exceeds }}$ that of sea water, when they would immediately form plunging flows (Mulder \& Syvitski, 1995). Faster flowing rivers are able to erode and carry more sediment, so it is expected that if underflows could form, it is during flooding events. Empirical data has often be used to find a relationship between the suspended sediment concentration $\left(C_{\underline{s}}\right.$ with units of $\left.\mathrm{kg} \mathrm{m}^{-3}\right)$ and the flow rate of the river $\left(Q\right.$ with units of $\mathrm{m}^{3} \mathrm{~s}^{-1}$ ) of the form

$$
\underline{C}_{S} \equiv \underline{a} \underline{Q}^{\underline{b}}
$$

where $a$ and $b$ are empirical rating coefficients. Furthermore, Mulder \& Syvitski (1995) show that the increased concentration of sediment during a flood $\left(C_{S \text { Flood }}\right)$ is related to the average $\underline{\text { concentration } C_{\underline{s}} \text { Average } \underline{\text { as }}}$

$$
\underline{C} \underline{S \text { Flood }} \equiv-\underline{C_{S \text { Average }}}\left(\frac{\underline{Q}_{\text {Flood }}}{\underline{Q}_{\text {Average }}}\right)^{\underline{b}}
$$

where $Q_{\text {Flood }}$ and $Q_{\text {Average }}$ are the flow rates during a flood and average conditions. An underflow would occur if $C_{\underline{s}}>\Delta \rho_{\text {SeaWater }}$. For typical $15^{\circ} \mathrm{C}$ and $35 \mathrm{ppt}$ salinity seawater the density

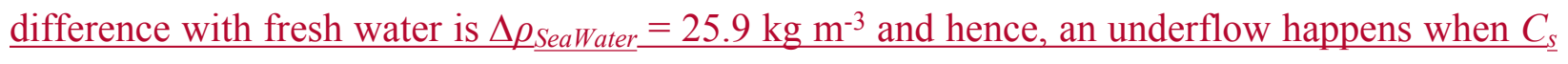
$\geq 25.9 \mathrm{~kg} \mathrm{~m}^{-3}$. Mulder \& Syvitski (1995) show that a large number of "moderately dirty" rivers could produce underflows (i.e. $R_{\rho}<1$ ) with $b<1$ (Table 3 in Mulder \& Syvitski 1995). For "moderately clean" rivers on the other hand, many would need to have $1<b \leq 1.5$ (Table 4 in Mulder \& Syvitski 1995) to occasionally produce underflows, whereas "relatively clean" rivers would need $1.5<b \leq 2$ (Table 5 in Mulder \& Syvitski 1995) to ever be able to form underflows.

One of the key results of this experiment was to identify that there is a distance over which a surface buoyant plume would lose most of its sediment. Hence, rather than an underflow requiring that a river be denser than seawater, previous papers have suggested that settlingdriven convection should allow the sediment in many rivers to be able to convert to a turbid underflow (i.e. Parsons et al., 2001). In order to use the scaling of Equation (14) to estimate the length-scale of propagation of a buoyant plume, the density ratio can be re-written as 


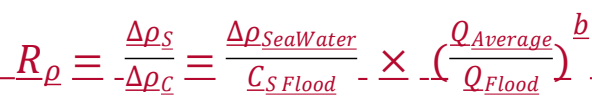

Therefore, while the condition of Mulder \& Syvitski (1995) requires $R_{p_{-}} \leqq 1$ for underflow formation, the experiments conducted in this study show that in many cases a secondary turbidity current can form in a distance that increases with $R_{p}$.

It is helpful to consider when there might be sufficient sediment load in the Squamish River in BC, Canada to form underflows (Fig. 11). This particular river is a good example of a sedimentladen river that is known to form periodic underflows (Hizzett et al. 2017). Data from Table 3 in Mulder \& Syvitski (1995) suggests that $C_{\text {s Average }}=1 \mathrm{~kg} \mathrm{~m}^{-3}, Q_{\text {Average }}=58 \mathrm{~m}^{3} \mathrm{~s}^{-1}$ and $b \leqq 1$ for this river. In this case, assuming $b=1$, then when $Q_{\text {Flood }}=1502 \mathrm{~m}^{3} \mathrm{~s}^{-1}$, the ratio $Q_{\text {Flood }} / Q_{\text {Average }} \equiv$ 25.9 would predict $R_{\underline{\rho}}=1$. Any higher flow rate would have $R_{\underline{\rho}} \leq 1$ and so for all higher values of $Q$ a plunging flow would form. For normal flow conditions however, the density of suspended

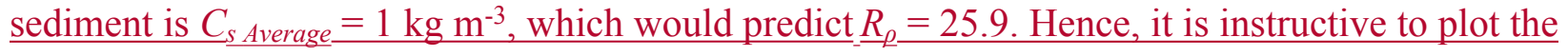
predicted length-scale $\left(L_{p r o p}\right)$ as a function of flow rate values $(Q)$ in Figure 11. In this figure, depth of the river is assumed to be $H=10 \mathrm{~m}$ (note that the constant in Equation (11) depends on $H^{1 / 2}$ and hence the result is not very sensitive to exact choice of this values, which would also fluctuate with tides). In Using Equation (11), the predicted length-scale of deposition for the Squamish River is $136 \mathrm{~m}$ for the average flow rate value of $Q_{\text {Average }}=58 \mathrm{~m}^{3} \mathrm{~s}^{-1}$, and up to $1-2$ $\mathrm{km}$ for lower flow rate values (Fig. 11). While there are no direct observations of settling-driven convection below the Squamish River, the predicted length-scales of 100 s to 1000 s of meters are broadly consistent with the distributions of sediment from the Squamish River within Howe Sound (i.e. Figure 2 in Gales et al. 2018). The exact relationship between $R_{\rho}$ and $Q$ for a specific river would require more research - for instance the average value of observed suspended sediment concentrations made by Hughes Clarke et al. (2014) was $0.07 \mathrm{~kg} \mathrm{~m}^{-3}$ in the Squamish River, notably less than the value of $C_{S \text { Average }}=1 \mathrm{~kg} \mathrm{~m}^{-3}$ described by Mulder \& Syvitski (1995).

\section{Important differences between laboratory experiments and the field}

The real world is much more complicated than the idealized experiments performed in this paper. The major benefit of laboratory experiments is that they can be used to study one specific 
process in isolation so that the controlling parameters can be quantified. On the other hand, the disadvantage is that when applying such scaling of the length-scale to a field setting, there may be many other processes that could also be important. Hence, it is critical to discuss the significant differences that might influence the interpretation of results in this paper. One important difference is that the current set of experiments had a finite volume of sediment-laden fluid that entered the ambient - these are the so-called "dam break" experiments and are widely used in fluid dynamics laboratory experiments (i.e. Turner, 1979; Simpson, 1982; Gladstone \& Pritchard, 2010). A real river however has a constant inflow, with new material continuously being pushed out from the river mouth. Therefore, even if most of the sediment is settling out from the river plume in a distance $L_{\text {prop }}$, the surface layer would still be pushed out by the continuous supply of water. Hence, the surface plume could continue to move out into the water body many kilometers, even after settling has occurred. Thus, the length-scales shown in Figure $\underline{11 \mathrm{~B} \text { are probably lower bounds on what the length-scale of the surface plume would look like in }}$ the field. In addition, Equation (11) implicitly assumes that the plume only spreads in one dimension, as in the laboratory. This is probably a reasonable assumption for the Squamish River spreading in the long fjord of Howe Sound, but in many coastal settings, river plumes are unconstrained and will spread in two-dimensions (Horner-Devine et al., 2015). Secondary turbidity currents are also more likely to occur when there is a sloping bottom, as opposed to the uniform depth in these experiments. For instance the experimental setup in the studies made by Parsons et al. (2001), Snow \& Sutherland (2014) and Sutherland et al. (2018) all included a sloping ramp, which would probably increase the tendency to form turbidity currents beneath an overflow.

Another critical process that occurs when fine river sediments meet the ocean is flocculation, which can also dramatically increase settling rates as flocs of particles sink faster than an individual particle. Flocculation is typically promoted at the pycnocline due to ionic exchange and other processes, so where fresh water enters a saline body, flocculation may be more likely. The increases in settling of sediment particles by flocculation could be occurring at the same time as settling-driven convection, so future work would need to determine the relative importance of such processes in estuaries. In real rivers there will also be a distribution of sediment particle size, rather than the uniform particles used in this study. Larger particles can 
$\underline{\text { sink into the "nose region" of Figure 2B faster than small particles, so there is weak dependence }}$ on the instability time-scale of Equation (9), as observed in the 3D simulations of Burns \& Meiburg (2015) and experimental observations of Sutherland et al. (2018). While some numerical work (i.e., Burns \& Meiburg, 2012, 2015; Yu et al., 2014, 2015) and experimental studies (Sutherland et al., 2018) have suggested a weak dependence of the vigour of settlingdriven convection on particle size, this remains an important area of future work. The main effect of a particle distribution will be some degree of fractionation of particles, with the larger particles being deposited closer to river mouth, and smaller particles settling at great differences from river mouth.

Tidal currents have also been shown to be somewhat important in triggering of turbidity currents in locations in British Columbia such as the Squamish River (Clare et al., 2016) and the Fraser delta (Ayranci et al., 2012; Lintern et al., 2016). While Clare et al. (2016) found that surface sediment-laden plumes at Squamish were linked to $\sim 70 \%$ of all turbidity currents; the precise timing was also strongly affected by tidal elevation. At low tides at Squamish, more (and coarser) sediment was flushed off the delta top, which increased the sediment flux and had higher settling rate due to coarser grains being transported. This tidal influence overprints the original signature of river discharge (Clare et al., 2016). At low tides, it is also possible that the shallow water depth may also promote formation of turbidity currents as there would be less dilution of the sediment-laden convective fingers, similar to how the sloping ramp promoted the formation of turbidity currents in experiments of Parsons et al. (2001), Snow \& Sutherland (2014) and Sutherland et al. (2018).

\section{Possible applications of experiments to other systems}

A recent paper by Stack et al. (2018) has tried to extrapolate some of the dynamics of sediment-laden rivers on Earth to understand ancient geological formations on Mars that possibly formed underwater. Specifically when trying to explain the geology of the Murray formation they speculate about the conditions under which an ancient Martian river could form an underflow in the Gale crater. A starting point for their discussion is that the evidence for geological deposits associated with a plunging river plume implies that the density of the river water be greater than that of the receiving waters (i.e. that $R_{\rho_{-}} \leqq 1$ ). From various estimates of 
the possible sediment load in river they draw inferences as to how salty the water body could have been. The analysis in this paper hopefully shows that in many situations plunging underflows can also form for $R_{p}>1$ due to the active settling-driven convection at the base of the overflow. Hence, the estimates by Stack et al. (2018) of the salinity of ancient water bodies in the Gale crater are possibly lower bounds, which have important implications for life on Mars.

A final area where the dynamics of settling-driven convection is relevant is in the dynamics of pyroclastic flows, especially in how a hot volcanic ash cloud might intrude into the thermally stratified atmosphere. Indeed the current work is related to previous experiments of Carazzo \& Jellinek (2012, 2013), Manzella et al. (2015) and Scollo et al. (2017), who studied the dynamics of settling-driven convection in order to interpret field observations of ash-laden volcanic clouds. In particular, geologists often wish to know the radius over which ash will deposit, as this has important hazard prediction implications. Equation (11) could be used to help estimate this radius - the major difference being that the air has a much lower viscosity than water, which will tend to enhance the rate at which the instability forms. The video imagery provided in the Supplementary material might further help interpret the finger like sediment plumes often seen in field observations of volcanic ash clouds (Scollo et al., 2017).

\section{CONCLUSION}

The main finding of this paper is that settling-driven convection can result in the rapid loss of sediment below a buoyant plume. The length-scale of sediment deposition is determined by the length-scale over which the plume propagates, and the faster sediment loss due to settling-driven convection results in a far smaller propagation length-scale compared to a simple estimate made by the Stokes settling velocity. The vertical settling of dense sediment-laden plumes was measured to be as much as 100 times that of the Stokes settling velocity of an individual particle. For density ratios close to unity, the propagation length-scale was small and an intense underflow or interflow emerged, which propagated longer distance than the surface plume. However, when density ratio was larger than one this length-scale increased as $R_{\underline{Q}}^{2 / 3}$. For a given salt stratification in an estuary, or thermal stratification in a lake, the sediment difference between the surface and deep layers will determine the strength of settling-driven convection. 
The sediment load in a river can be estimated by using a rating curve for the sediment load as a function of river flow rate $(O)$. Hence, it is possible to estimate the density ratio $\left(R_{\rho}\right)$ as a function of $Q$ for a river flowing into a salty ocean. Equation (11) can then be used to predict the length-scale over which sedimentation could occur, as was done in the example of the Squamish River. In these oceanic cases it is reasonable to ignore temperature effects, as large salinity differences dominate the density differences. To make the same estimates using Equation (11) for a lake, it would also require that the temperature of the river and the seasonal thermal stratification of the lake be known. For example, Cossu et al. (2015) discussed how the seasonality in sediment loading in rivers and changes of the thermal stratification in an alpine lake could greatly influence whether overflows, interflows or underflows occurred. Hopefully, future research into these processes will include measurements of the density ratio, and the design of field observations can be guided by the predictions of Equation (11) and the time-lapse movies contained in the Supplemental section.

\section{ACKNOWLEDGMENTS}

$\underline{\text { We acknowledge constructive comments from Dr. Mike Clare and two anonymous reviewers }}$ that were very helpful in revising this article. M. G. Wells was funded through the NSERC Discovery program grant (RGPIN-2016-06542). 


\section{NOMENCLATURE}

\begin{tabular}{|c|c|}
\hline$a$ & Empirical rating coefficient \\
\hline$b$ & Empirical rating coefficient \\
\hline C & Average concentration of the flow $\left(\mathrm{kg} \mathrm{m}^{-3}\right)$ \\
\hline$C_{s}$ & Concentration of suspended sediment $\left(\mathrm{kg} \mathrm{m}^{-3}\right)$ \\
\hline$C_{s \text { Average }}$ & Average concentration of suspended sediment $\left(\mathrm{kg} \mathrm{m}^{-3}\right)$ \\
\hline$C_{s \text { Flood }}$ & Concentration of suspended sediment during a flood $\left(\mathrm{kg} \mathrm{m}^{-3}\right)$ \\
\hline$c_{t}$ & $\begin{array}{l}\text { Dimensionless multiple of time that takes for settling-driven convection to } \\
\text { develop }\end{array}$ \\
\hline$C_{0}$ & Initial concentration of the flow $\left(\mathrm{kg} \mathrm{m}^{-3}\right)$ \\
\hline$c_{1}$ & $1^{\text {st }}$ dimensional constant $\left(\mathrm{m} \mathrm{s}^{-1}\right)$ \\
\hline$c_{\text {lavg }}$ & Average value of the $1^{\text {st }}$ dimensional constants $\left(\mathrm{m} \mathrm{s}^{-1}\right)$ \\
\hline$c_{2}$ & $2^{\text {nd }}$ dimensional constant $(\mathrm{s})$ \\
\hline$c_{2 a v g}$ & Average value of the $2^{\text {nd }}$ dimensional constants (s) \\
\hline $\mathrm{Fr}$ & Froude number \\
\hline$g$ & Gravitational acceleration $\left(9.81 \mathrm{~m} \mathrm{~s}^{-2}\right)$ \\
\hline$g^{\prime}$ & Reduced gravity $\left(\mathrm{m} \mathrm{s}^{-2}\right)$ \\
\hline$g_{C}^{\prime}$ & Reduced gravity in terms of density difference due to the added sediment $\left(\mathrm{m} \mathrm{s}^{-2}\right)$ \\
\hline $\mathrm{Gr}$ & Grashof number \\
\hline$H$ & Thickness of the current (m) \\
\hline $\bar{H}$ & Mean thickness of the current (m) \\
\hline$L_{C}$ & Thickness of the nose region $(\mathrm{m})$ \\
\hline$L_{\text {prop }}$ & Propagation length-scale of the current (m) \\
\hline$m_{C}$ & Mass of sediment particles $(\mathrm{kg})$ \\
\hline$m_{\text {comp }}$ & Mass of the water in the small compartment $(\mathrm{kg})$ \\
\hline$Q$ & The flow rate of a river $\left(\mathrm{m}^{3} \mathrm{~s}^{-1}\right)$ \\
\hline$Q_{\text {Average }}$ & Average flow rate of a river $\left(\mathrm{m}^{3} \mathrm{~s}^{-1}\right)$ \\
\hline$Q_{\text {Flood }}$ & Flow rate of a river during flood $\left(\mathrm{m}^{3} \mathrm{~s}^{-1}\right)$ \\
\hline $\operatorname{Re}$ & Reynolds number \\
\hline$R_{\rho}$ & Density ratio \\
\hline
\end{tabular}




\section{NOMENCLATURE CONTINUED}

\begin{tabular}{|c|c|}
\hline$T_{S}$ & Settling time-scale of sediment particles (s) \\
\hline$t$ & Time (s) \\
\hline$t_{\text {comp }}$ & Temperature of the small compartment $\left({ }^{\circ} \mathrm{C}\right)$ \\
\hline$t_{S}$ & Temperature of the saline ambient $\left({ }^{\circ} \mathrm{C}\right)$ \\
\hline$t_{0}$ & Time corresponding to the initial stable density profile (s) \\
\hline$U$ & Horizontal velocity of the current $\left(\mathrm{m} \mathrm{s}^{-1}\right)$ \\
\hline$V_{\text {comp }}$ & Volume of the compartment $\left(\mathrm{m}^{3}\right)$ \\
\hline$w$ & Vertical velocity of the fluid in the nose region $\left(\mathrm{m} \mathrm{s}^{-1}\right)$ \\
\hline$w_{S}$ & Stokes settling velocity of sediment particles $\left(\mathrm{m} \mathrm{s}^{-1}\right)$ \\
\hline$\Delta \rho$ & Density difference between the current and the saline ambient $\left(\mathrm{kg} \mathrm{m}^{-3}\right)$ \\
\hline$\Delta \rho_{C}$ & Density differences due to the added sediment $\left(\mathrm{kg} \mathrm{m}^{-3}\right)$ \\
\hline$\Delta \rho_{S}$ & Density differences due to the added salt $\left(\mathrm{kg} \mathrm{m}^{-3}\right)$ \\
\hline$\Delta \rho_{\text {SeaWater }}$ & Density difference due to the added salt for sea water at $15^{\circ} \mathrm{C}$ \\
\hline$\Delta t$ & Elapsed time between the stable and the unstable density profiles (s) \\
\hline$\varphi$ & Mass concentration of sediment particles $\left(\mathrm{kg} \mathrm{kg}^{-1}\right)$ \\
\hline$\gamma$ & Density expansion coefficient for $\mathrm{SiC}$ particles \\
\hline$v$ & Coefficient of kinematic viscosity of fresh water at $20^{\circ} \mathrm{C}\left(10^{-6} \mathrm{~m}^{2} \mathrm{~s}^{-1}\right)$ \\
\hline$\rho$ & Average density between the current and the saline ambient $\left(\mathrm{kg} \mathrm{m}^{-3}\right)$ \\
\hline$\rho_{C}$ & Density of the sediment-laden water $\left(\mathrm{kg} \mathrm{m}^{-3}\right)$ \\
\hline$\rho_{\text {comp }}$ & Density of the small compartment before adding sediment $\left(\mathrm{kg} \mathrm{m}^{-3}\right)$ \\
\hline$\rho_{f}$ & Total density of a fluid $\left(\mathrm{kg} \mathrm{m}^{-3}\right)$ \\
\hline$\rho_{S}$ & Density of the saline ambient $\left(\mathrm{kg} \mathrm{m}^{-3}\right)$ \\
\hline$\rho_{S i C}$ & Density of SiC particles $\left(3210 \mathrm{~kg} \mathrm{~m}^{-3}\right)$ \\
\hline$\rho_{0}$ & Density of clear fresh water at $20^{\circ} \mathrm{C}\left(998.2 \mathrm{~kg} \mathrm{~m}^{-3}\right)$ \\
\hline
\end{tabular}




\section{REFERENCES}

Ayranci, K., Lintern, D.G., Hill, P.R. and Dashtgard, S.E. (2012) Tide-supported gravity flows on the upper delta front, Fraser River delta, Canada. Mar. Geol., 326, 166 - 170.

Benjamin, T.B. (1968) Gravity currents and related phenomena. J. Fluid Mech., 31, 209 - 248.

Burns, P. and Meiburg, E. (2012) Sediment-laden fresh water above salt water: Linear stability analysis. J. Fluid Mech., 691, $279-314$.

Burns, P. and Meiburg, E. (2015) Sediment-laden fresh water above salt water: Nonlinear stability analysis. J. Fluid Mech., 762, $156-195$.

Carazzo, G. and Jellinek, A.M. (2012) A new view of the dynamics, stability and longevity of volcanic clouds. Earth Planet. Sci. Lett., 325 - 326, 39 - 51.

Carazzo, G. and Jellinek, A.M. (2013) Particle sedimentation and diffusive convection in volcanic ash-clouds. J. Geophys. Res. Solid Earth, 18, 1420 - 1437, doi:10.1002/jgrb.50155.

Chen, C.F. (1997) Particle flux through sediment fingers. Deep Sea Res., 44 (9 - 10), 1645 1654.

Clare, M.A., Clarke, J.H., Talling, P.J., Cartigny, M.J.B. and Pratomo, D.G. (2016) Preconditioning and triggering of offshore slope failures and turbidity currents revealed by most detailed monitoring yet at a fjord-head delta. Earth Planet. Sci. Lett., 450, $208-220$.

Cossu, R., Forrest A.L., Roop, H.A., Dunbar, G.B., Vandergoes, M.J., Levy, R.H., Stumoner, P. and Schladow, S. G. (2015) Seasonal variability in turbidity currents in Lake Ohau, New Zealand, and their influence on sedimentation. Mar. Freshwater Res., doi:10.1071/MF15043.

Davarpanah Jazi, S. and Wells, M.G. (2016) Enhanced sedimentation beneath particle-laden flows in lakes and the ocean due to double-diffusive convection. Geophys. Res. Lett., 43 (20), 10883 - 10890, doi: 10.1002/2016GL069547.

Forel, F.A. (1885) Les ravins sous-lacustres des fleuves glaciaires. Comptes Rendus de l'Académie des Sciences de Paris: 1-3.

Geyer, W.R., Hill, P.S. and Kineke, G.C. (2004) The transport, transformation and dispersal of sediment by buoyant coastal flows. Cont. Shelf Res., 1212 (24), 927 - 949.

Gilbert, R. and Butler, R.D. (2004) The physical limnology and sedimentology of Meziadin Lake, northern British Columbia, Canada. Arct. Antarct. Alp. Res., 36 (1), 33 - 41. 
Giovanoli, F. (1990) Horizontal transport and sedimentation by interflows and turbidity currents in Lake Geneva. In Large Lakes, edited by Tilzer, M. M. and Serruya, C., pp. 175 - 195, Springer, Berlin.

Gladstone, C. and Pritchard, D. (2010) Patterns of deposition from experimental turbidity currents with reversing buoyancy. Sedimentology, 57, $53-84$.

Green, T. (1987) The importance of double diffusion to the settling of suspended material. Sedimentology, 34, $319-331$.

Hill, P.S., Milligan, T.G. and Geyer, W.R. (2000) Controls on effective settling velocity of suspended sediment in the Eel River flood plume, Cont. Shelf Res., 20 (16), 2095 - 2111.

Hill, P.R., Conway, K., Lintern, D.G., Meulé, S., Picard, K. and Barrie, J.V. (2008) Sedimentary processes and sediment dispersal in the southern Strait of Georgia, BC, Canada. Mar. Environ. Res., 66, S39 - S48.

Hizzett, J.L., Hughes Clarke, J.E., Sumner, E.J., Cartigny, M.J.B., Talling, P. J. and Clare, M.A. (2017) Which triggers produce the most erosive, frequent and longest runout turbidity currents on deltas? Geophys. Res. Lett., 45, doi: 10.1002/2017GL075751.

Horner-Devine, A.R., Hetland, R.D. and MacDonald, D.G. (2015) Mixing and transport in coastal river plumes. Annu. Rev. Fluid Mech., 47, 569 - 594.

Houk, D. and Green, T. (1973) Descent rates of suspension fingers. Deep Sea Res., 20, 757 761.

Hoyal, D.C.J.D., Bursik, M.I. and Atkinson, J.F. (1999a) The influence of diffusive convection on sedimentation from buoyant plumes. Mar. Geol., 159, 205 - 220.

Hoyal, D.C.J.D., Bursik, M.I. and Atkinson, J.F. (1999b) Settling-driven convection: A mechanism of sedimentation from stratified fluids. J. Geophys. Res., 104 (C4), 7953 - 7966, doi: 10.1029/1998JC900065.

Huppert, H.E. (2006) Gravity currents: a personal perspective. J. Fluid Mech., 554, 299 - 322.

Hughes Clarke, J.E., Marques, C.R.V. and Pratomo, D. (2014) Imaging active mass-wasting and sediment flows on a fjord delta, Squamish, British Columbia. In Submarine Mass Movements and Their Consequences, 249 - 260, Springer.

Kineke, G. C., Woolfe, K. J., Kuehl, S. A., Milliman, J. D., Dellapenna, T. M. and Purdon, R. G. (2000) Sediment export from the Sepik River, Papua New Guinea: evidence for a divergent sediment plume. Cont. Shelf Res., 20 (16), 2239 - 2266.

Lintern, D. G., Hill, P. R. and Stacey, C. (2016) Powerful unconfined turbidity current captured by cabled observatory on the Fraser River delta slope, British Columbia, Canada. Sedimentology, 
$63(5), 1041-1064$.

Manzella, I., Bonadonna, C., Phillips, J.C. and Monnard, H. (2015) The role of gravitational instabilities in deposition of volcanic ash. Geology, 43 (3), $211-214$.

Martin, D. and Nokes, R. (1998) Crystal settling in a vigorously convecting magma chamber. Nature, 332,534-536.

Maxworthy, T. (1999) The dynamics of sedimenting surface gravity currents. J. Fluid Mech., 392, $27-44$.

Meiburg, E. and Kneller, B.C. (2010) Turbidity currents and their deposits. Annu. Rev. Fluid Mech., 42, 135 - 156.

Mulder, T. and Chapron, E. (2011) Flood deposits in continental and marine environments: character and significance. In Sediment Transport from Shelf to Deep Water - Revisiting the Delivery System, AAPG Stud. Geol., vol. 61, edited by R. M. Slatt and C. Zavala, pp. 1 - 30.

Mulder, T. and Syvitski, J.P.M. (1995) Turbidity currents generated at river mouths during exceptional discharges to the world oceans. J. Geol., 103 (3), 285 - 299.

Nowacki, D.J., Horner-Devine, A.R., Nash, J.D. and Jay, D.A. (2012) Rapid sediment removal from the Columbia River plume nearfield. Cont. Shelf Res. 35, 16 - 28.

Parsons, J.D. and Garcia, M.H. (2000) Enhanced sediment scavenging due to double-diffusive convection. J. Sediment. Res., 70 (1), $47-52$.

Parsons, J.D., Bush, J.W.M. and Syvitski, J.P.M. (2001) Hyperpycnal plume formation from riverine outflows with small sediment concentrations. Sedimentology, 48 (2), $465-478$.

Penney, J. and Stastna, M. (2016) Direct numerical simulation of double-diffusive gravity currents. Physics of Fluids 28, 086602; doi: 10.1063/1.4961045.

Rouhnia, M. and Strom, K. (2015) Sedimentation from flocculated suspensions in the presence of settling-driven gravitational interface instabilities. J. Geophys. Res. Oceans, 120, 6384 - 6404, doi: 10.1002/2015JC010750.

Rouhnia, M. and Strom, K. (2017) Sedimentation from buoyant muddy plumes in the presence of interface mixing: an experimental study. J. Geophys. Res. Oceans, 120, 2652 - 2670, doi: 10.1002/2016JC012053.

Shao, Y.C., Hung, C.Y. and Chou, Y.J. (2017) Numerical study of convective sedimentation through a sharp density interface. J. Fluid Mech., 824, 513 - 549.

Scheu, K.R., Fong, D.A., Monismith, S.G. and Fringer, O.B. (2015) Sediment transport dynamics near a river inflow in a large alpine lake. Limnol. Oceanogr., 60 (4), 1195 - 1211. 
Simpson, J.E. (1982) Gravity currents in the laboratory, atmosphere and ocean. Ann. Rev. Fluid Mech., 14 (1), 213 - 234.

Snow, K. and Sutherland, B.R. (2014) Particle-laden flow down a slope in uniform stratification. J. Fluid Mech., 755, $251-273$.

Scollo, S., Bonadonna, C., and Manzella, I. (2017) Settling-driven gravitational instabilities associated with volcanic clouds: new insights from experimental investigations. Bulletin of Volcanology, 79:39. https://doi.org/10.1007/s00445-017-1124-X.

Sparks, R.S.J., Carey, S.N. and Sigurdsson, H. (1991). Sedimentation from gravity currents generated by turbulent plumes. Sedimentology, 38 (5), 839 - 856.

Stack, K. M., Grotzinger, J. P., Lamb, M. P., Gupta, S., Rubin, D. M., Kah, L. C., Edgar, L. A., Fey, D. M., Hurowitz, J. A., McBride, M., Rivera-Hernández, F., Sumner, D. Y., Van Beek, J. K., Williams, R. M. E., and Yingst, R. A. (2018) Evidence for plunging river plume deposits in the Pahrump Hills member of the Murray formation, Gale crater, Mars. Sedimentology, doi: 10.1111/sed.12558

Sutherland, B.R., Gingras, M.K., Knudson, C., Steverango, L. and Surma, C. (2018) Particle-bearing currents in uniform density and two-layer fluids. Phy. Rev. Fluids, 3 (2), p.023801.

Talling, P. J., Paull, C.K. and Piper, D.J.W. (2013) How are subaqueous sediment density flows triggered, what is their internal structure and how does it evolve? Direct observations from monitoring of active flows. Earth-Sci. Rev., 112, 244 - 288.

Turner, J. S. (1979) Buoyancy Effects in Fluids. Cambridge University Press.

Warrick, J. A., Xu, J., Marlene, A. N. and Homa, J. L. (2008) Rapid formation of hyperpycnal sediment gravity currents offshore of a semi-arid California river. Cont. Shelf Res., 28, 991 1009.

Yuan, Y. and Horner-Devine, A.R. (2017) Experimental investigation of large-scale vortices in a freely spreading gravity current. Phys. Fluids, 29(10), p.106603. https://doi.org/10.1063/1.5006176.

Yu, X., Hsu, T. J. and Balachandar, S. (2013) Convective instability in sedimentation: Linear stability analysis. J. Geophys. Res. Oceans, 118, 256 - 272, doi:10.1029/2012JC008255.

Yu, X., Hsu, T. J. and Balachandar, S. (2014) Convective instability in sedimentation: 3-D numerical study. J. Geophys. Res. Oceans, 119, 8141 - 8161, doi:10.1002/2014JC010123.

Zhixin, Q., Eames, I. and Greig, A. (2014) Flushing ballast tanks. Ocean Eng., 89, 157 - 172. 


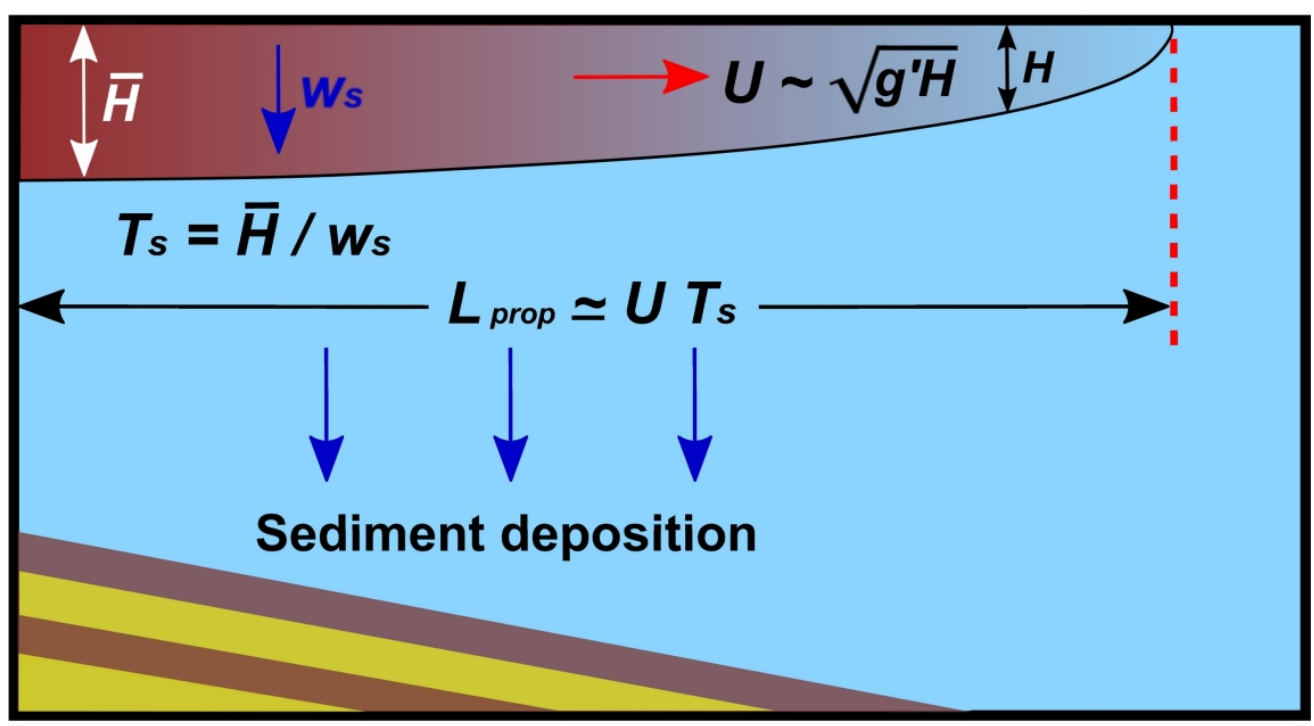

Fig. 1: A conceptual diagram of the relevant scales beneath a buoyant sediment-laden current that propagates on top of a saline ambient as an overflow from a river mouth. The length-scale of sediment deposition is determined by how far the buoyant sediment-laden plume will propagate before the sediment is lost. This current has a mean thickness of $H_{b a r}$, horizontal velocity of $U$ and propagation length of $L_{p r o p}$. The Stokes settling velocity of sediment particles within the current is $w_{S}$ and the settling time-scale of each sediment particle can be represented as $T_{S}$. 

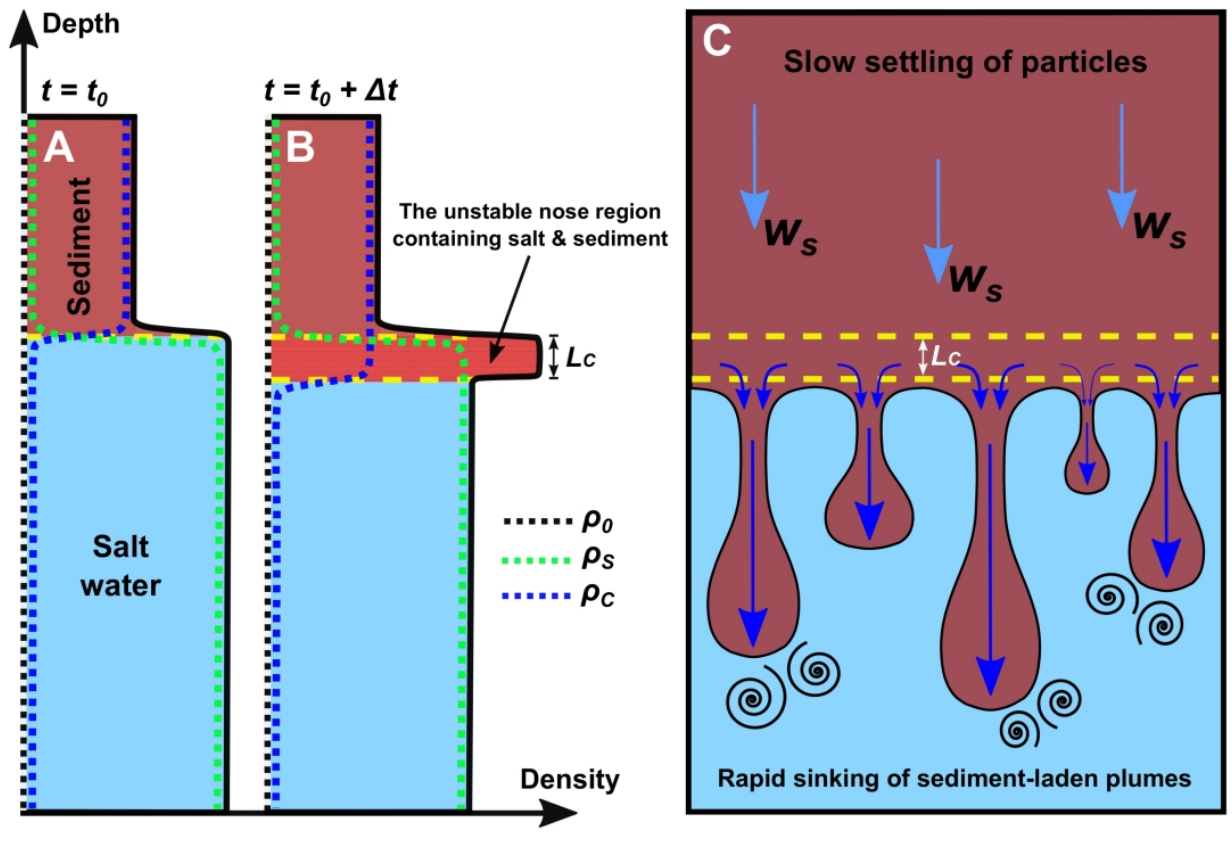

Fig. 2: A schematic representation of the instabilities that lead to settling-driven convection. (A) At time $t=$ $t_{0}$ the initial density profile is stable, with a lighter sediment-laden overflow above a dense saline layer. Here the added density due to the mass fraction of sediment $\left(\Delta \rho_{C}\right)$ is smaller everywhere than the added density due to the added salt $\left(\Delta \rho_{S}\right)$ resulting in a stable stratified salt/sediment configuration. (B) At a later time of

$t=t_{0}+\Delta t$, sediment has settled down producing an unstable nose region containing both salt and sediment. The density of fresh water, salt water and sediment water are specified by $\rho_{0}, \rho_{S}$ and $\rho_{C}$ respectively. The dotted green and blue lines indicate density of salt water $\left(\rho_{S}\right)$, sediment water $\left(\rho_{C}\right)$, while the solid black line represents the total density $\left(\rho_{f}\right)$. The thickness of the unstable nose region is shown as $L_{C}$, which has grown with time defined as $L_{C}=w_{S} \Delta t$ (Burns \& Meiburg, 2012). (C) The nose region can now become unstable, resulting in a process of vigorous settling-driven convection of sediment particles beneath the interface. The descending large finger-like plumes of sediment-laden material have vertical velocities of at least an order of magnitude faster than the Stokes settling velocity of a single particle $\left(w_{S}\right)$. 


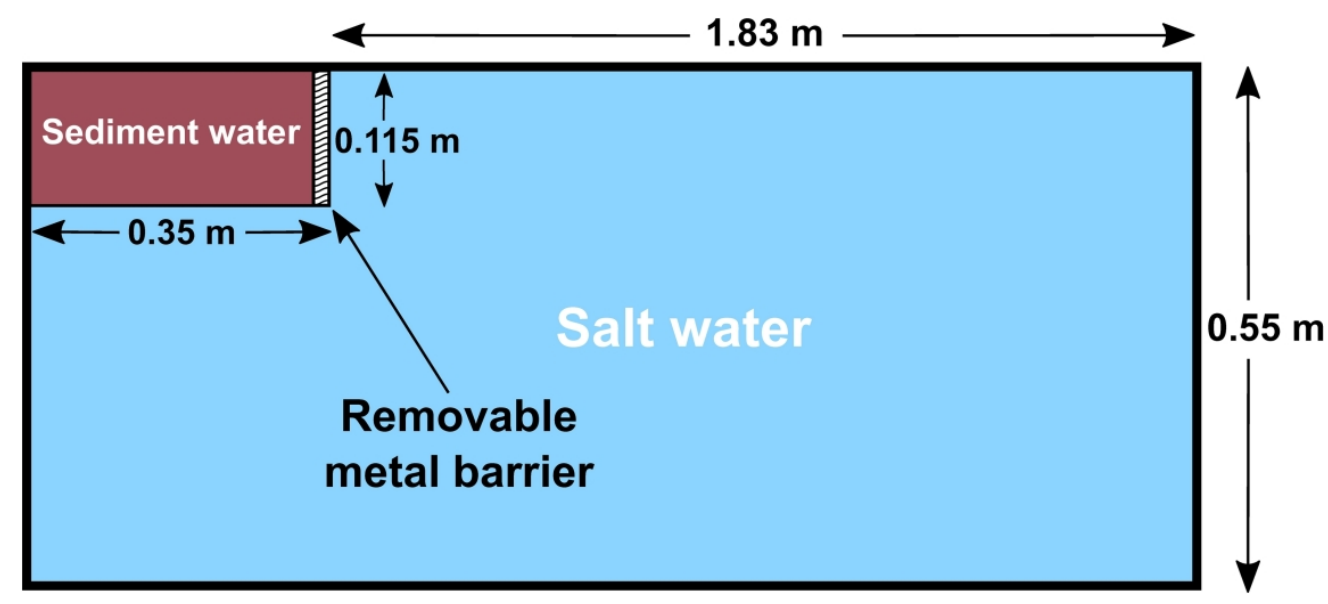

Fig. 3: Schematic side view of the experimental setup, showing the main tank (containing saline water), the small isolated compartment on the left-hand side (containing sediment water) and the removable metal barrier. When the barrier is removed, a layer of sediment-laden water propagates on top of the saline ambient, thus simulating the entrance of a buoyant river into a denser lake or the coastal ocean.

$288 \times 128 \mathrm{~mm}(300 \times 300 \mathrm{DPI})$ 
Table 1: The data corresponding to the conducted experiments

\begin{tabular}{lllllll}
\hline Exp. No. & $\boldsymbol{R}_{\boldsymbol{\rho}}$ & $\boldsymbol{t}_{\boldsymbol{s}}\left({ }^{\mathbf{0}} \mathbf{C}\right)$ & $\boldsymbol{t}_{\text {comp }}\left({ }^{\mathbf{0}} \mathbf{C}\right)$ & $\boldsymbol{m}_{\boldsymbol{C}}(\mathbf{k g})$ & $\boldsymbol{L}_{\boldsymbol{p r o p}}(\mathbf{m})$ & Flow behavior \\
\hline $\mathbf{1}$ & 0.687 & 16.8 & 16.2 & 0.065 & - & Strong underflow / Movie S1 \\
$\mathbf{2}$ & 1.021 & 18.2 & 18.2 & 0.045 & 0.65 & Fig. 9D \\
$\mathbf{3}$ & 1.054 & 18.7 & 18.8 & 0.041 & 0.75 & Fig. 9D / Movie S2 \\
$\mathbf{4}$ & 1.093 & 19.9 & 20.1 & 0.042 & 1 & Fig. 9D \\
$\mathbf{5}$ & 1.107 & 20.7 & 20.4 & 0.039 & 1.1 & Fig. 9D \\
$\mathbf{6}$ & 1.151 & 21 & 20.8 & 0.034 & 1.25 & Fig. 9D \\
$\mathbf{7}$ & 1.172 & 20.6 & 20.5 & 0.038 & 1.3 & Fig. 9C \\
$\mathbf{8}$ & 1.230 & 20.8 & 20.4 & 0.034 & 1.55 & Very weak version of Fig. 9D \\
$\mathbf{9}$ & 1.233 & 20.5 & 20.3 & 0.035 & 1.6 & Fig. 9C \\
$\mathbf{1 0}$ & 1.308 & 21 & 20.6 & 0.033 & 1.83 & Fig. 9B \\
$\mathbf{1 1}$ & 1.391 & 20.6 & 20.6 & 0.032 & 1.83 & Fig. 9B / Movie S3 \\
$\mathbf{1 2}$ & 1.433 & 18.7 & 18.8 & 0.032 & 1.83 & Fig. 9B / Movie S4 \\
$\mathbf{1 3}$ & 1.483 & 20.6 & 20.5 & 0.030 & 1.83 & Fig. 9B \\
$\mathbf{1 4}$ & 1.779 & 20.6 & 20.6 & 0.025 & 1.83 & Fig. 9B \\
$\mathbf{1 5}$ & 2.155 & 20.1 & 19.9 & 0.020 & 1.83 & Weak version of Fig. 9B \\
$\mathbf{1 6}$ & 2.492 & 17.4 & 19.3 & 0.020 & 1.83 & Fig. 9A \\
$\mathbf{1 0}$ & 3.051 & 19.8 & 19.7 & 0.015 & 1.83 & Fig. 9A \\
\hline & 4.575 & 18.5 & 18.7 & 0.010 & 1.83 & Fig. 9A / Movie S5 \\
\hline & 0 & 19.7 & 20.2 & 0 & 1.83 & Strong overflow / Movie S6 \\
\hline
\end{tabular}




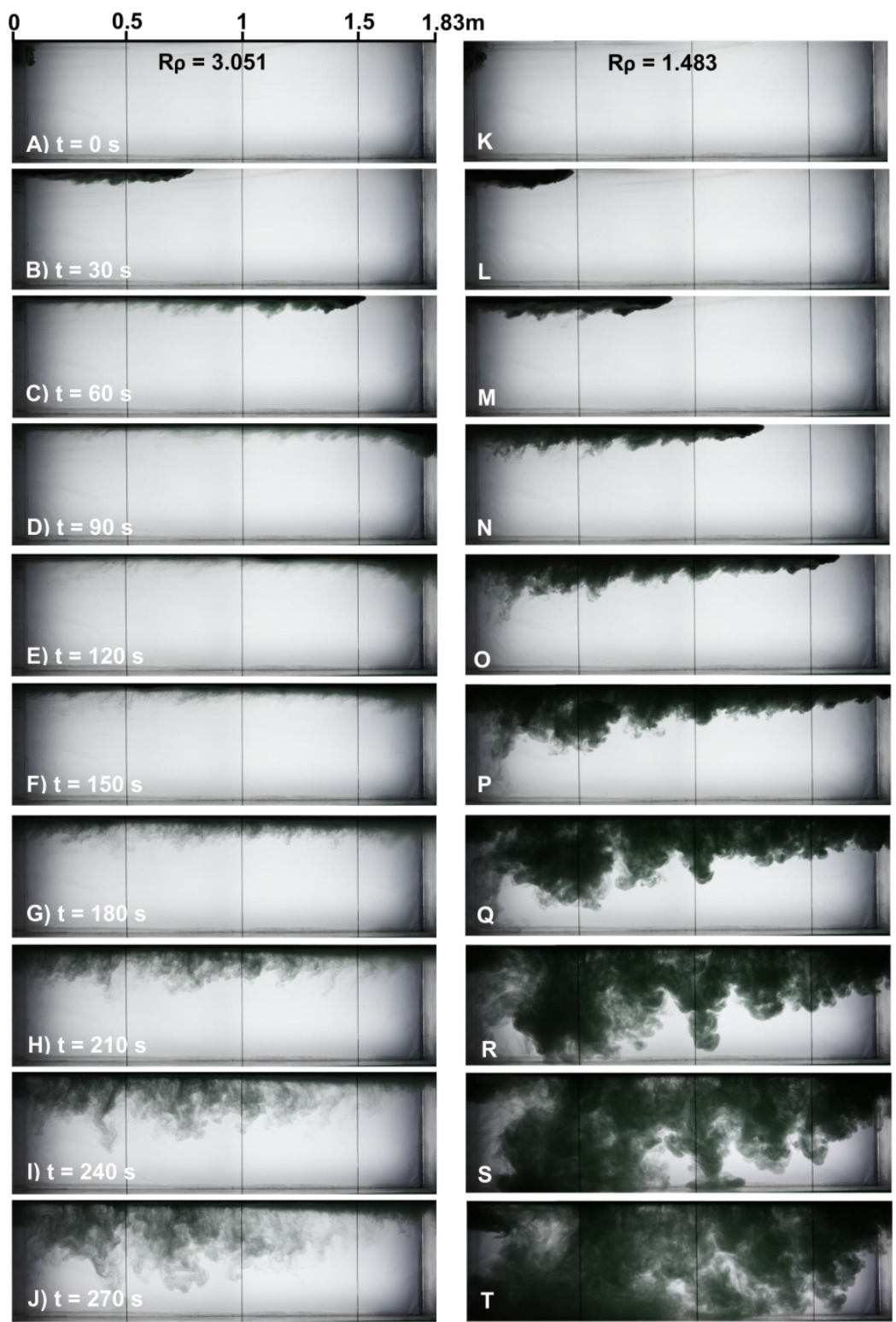

Fig. 4: There is a striking difference in behavior between weak settling-driven convection $\left(R_{\rho}=3.051\right.$, panels $(\mathrm{A})$ to $(\mathrm{J}))$ and vigorous settling-driven convection $\left(R_{\rho}=1.483\right.$, panels $(\mathrm{K})$ to $\left.(\mathrm{T})\right)$. The photos were taken every $30 \mathrm{~s}$ and show the differences in vertical velocities of settling-driven convection for the slower case of $R_{\rho}=3.051$ and the faster case of $R_{\rho}=1.483$. Movies S5 $\left(R_{\rho}=4.575\right)$ and S4 $\left(R_{\rho}=1.433\right)$ in the Supplemental section respectively show the weak and vigorous settling-driven convection. 


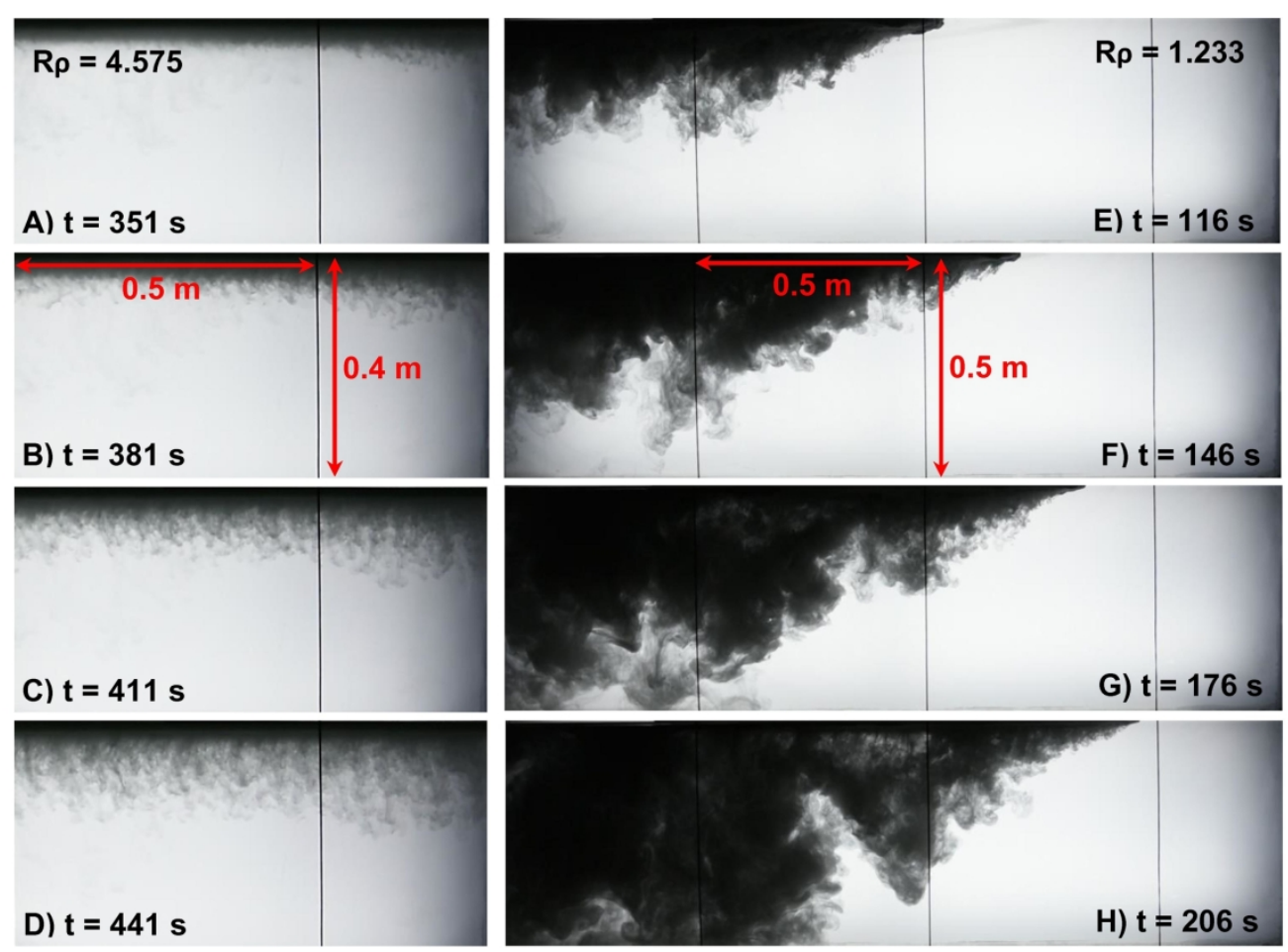

Fig. 5: A series of close up photos that emphasize the form of the settling-driven convection. These images were taken every $30 \mathrm{~s}$. Panels (A) to (D) show slow sinking sediment plumes due to weak settling-driven convection in an experiment with high density ratio $\left(R_{\rho}=4.575\right)$, while panels $(\mathrm{E})$ to $(\mathrm{H})$ depict faster sinking sediment fingers due to vigorous settling-driven convection in an experiment with low density ratio

$$
\left(R_{\rho}=1.229\right) \text {. }
$$



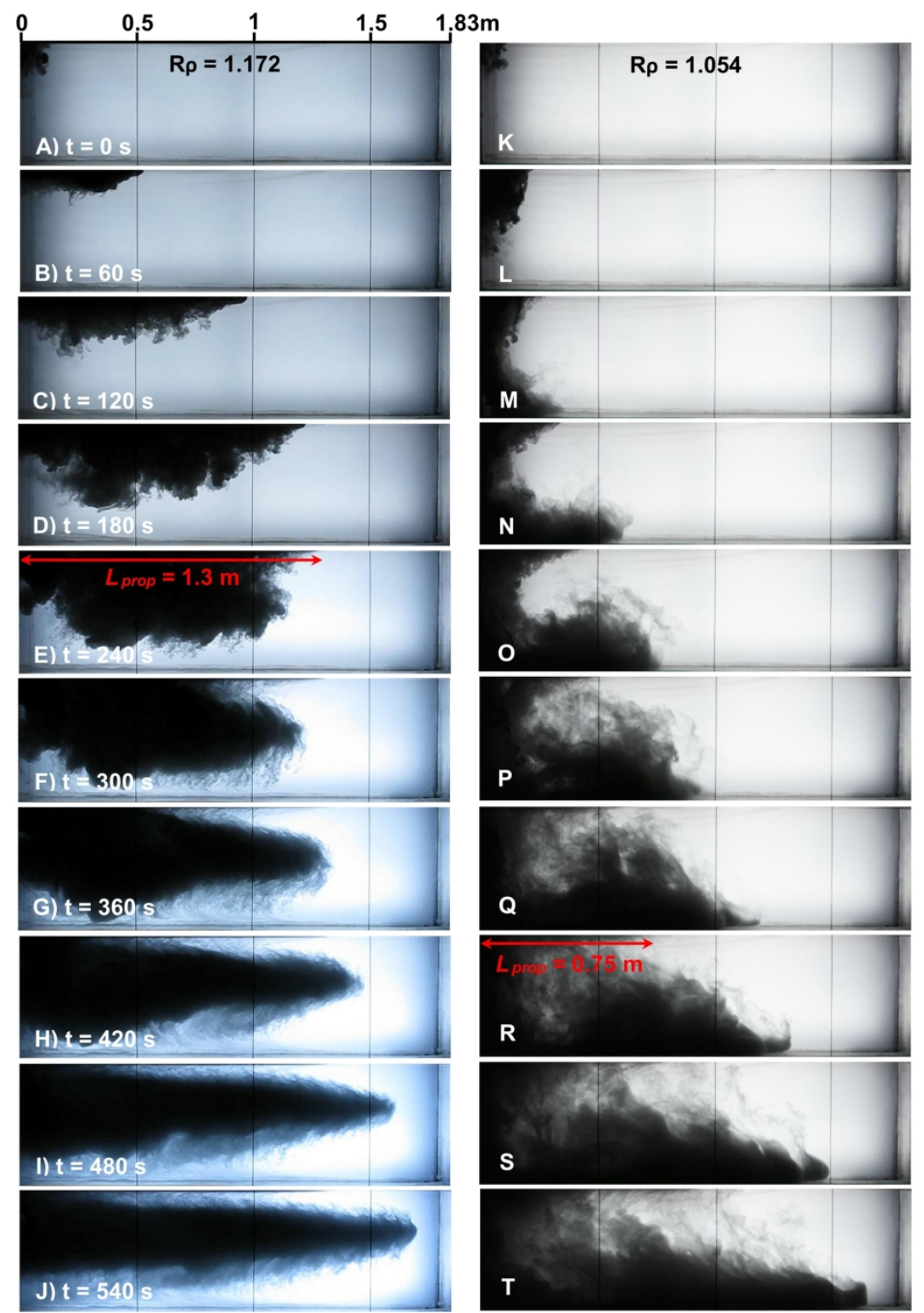

Fig. 6: Photos of experiments taken every $60 \mathrm{~s}$, which shows the formation of $(\mathrm{A})$ to $(\mathrm{J})$ an interflow $\left(R_{\rho}=\right.$ $1.172)$ and $(\mathrm{K})$ to $(\mathrm{T})$ an underflow $\left(R_{\rho}=1.054\right)$ from the descending mixture of sediment and freshwater into the saline body. In both cases the surface current never reached the end of the tank and stopped before reaching a distance of $1.5 \mathrm{~m}$, as the sediments settled rapidly due to the strongly vigorous settling-driven convection of $\mathrm{SiC}$ particles. In Figure $6 \mathrm{E}$ the overflow stopped at $1.3 \mathrm{~m}$, whereas in Figure 6R it stopped at $0.75 \mathrm{~m}$. Movies S2 $\left(R_{\rho}=1.054\right)$ and S3 $\left(R_{\rho}=1.391\right)$ in the Supplemental section respectively show the emergence of a secondary underflow and interflow. 

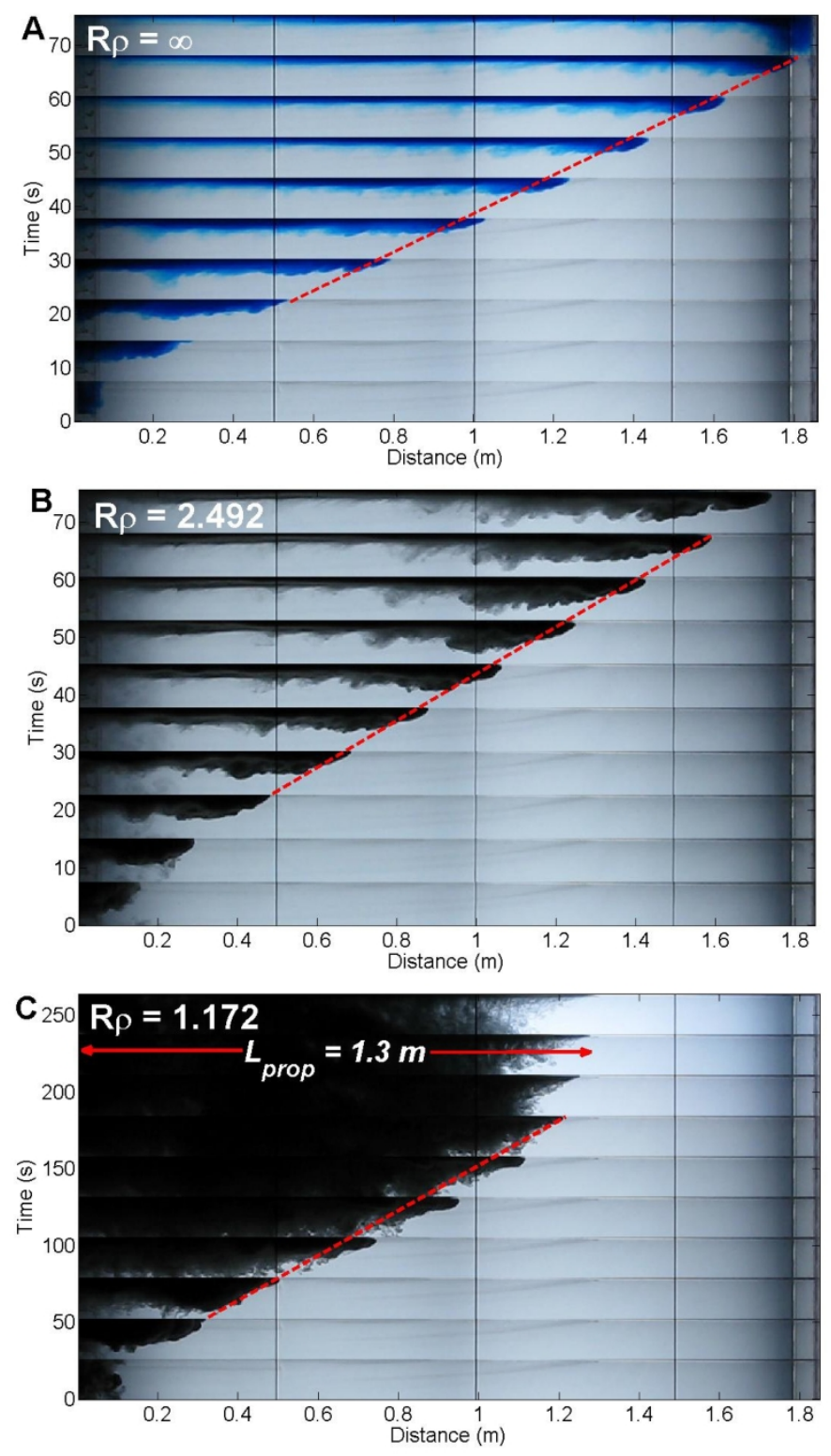

Fig. 7: A time-series of photos taken from the top $0.127 \mathrm{~m}$ of the overflow to compare the propagation speed of the gravity current for different density ratios in (A) $R_{\rho}=\infty$ (speed $=0.0279 \mathrm{~m} \mathrm{~s}^{-1}$ ), (B) $R_{\rho}=$ 2.492 (speed $=0.0246 \mathrm{~m} \mathrm{~s}^{-1}$ ) and (C) $R_{\rho}=1.172$ (speed $=0.0068 \mathrm{~m} \mathrm{~s}^{-1}$ ), where the gravity current stops at $L_{\text {prop }}=1.3 \mathrm{~m}$. The speed of the overflow was determined by fitting the best line to the front of the current in each stack of images. A comparison of the initial speed of the propagating overflow in the three figures shows a faster speed for the larger density ratios that have larger density contrast, which is consistent with the scaling of Equation (3). 


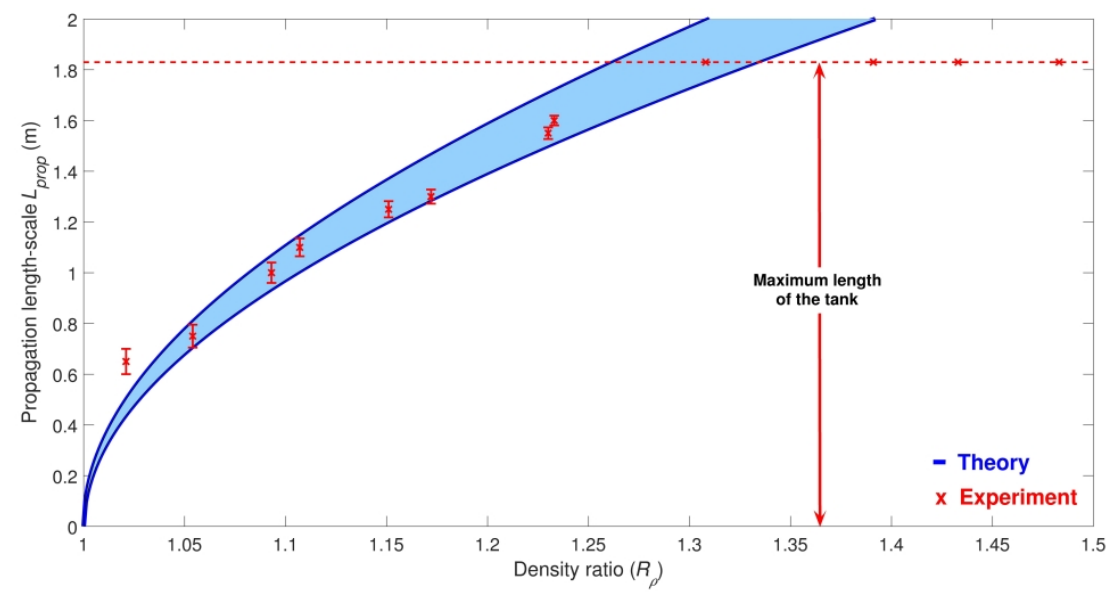

Fig. 8: A comparison of theoretical predictions and experimental observations of the propagation lengthscale ( $L_{\text {prop }}$ ) of the gravity current as a function of various density ratios $\left(R_{\rho}\right)$. Decreasing $R_{\rho}$ towards unity results in a decrease in $L_{\text {prop }}$. The two curves for the theory represent a realistic range of values between $c_{1 a v g}=0.0462 \mathrm{~m} \mathrm{~s}^{-1}, c_{2 a v g}=0.1489 \mathrm{~s}$, and $c_{t}=440$ and 500 for the coefficient in Equation (11). The length of the tank is $1.83 \mathrm{~m}$, limiting the maximum propagation length-scale of the experiments.

$507 \times 242 \mathrm{~mm}(300 \times 300 \mathrm{DPI})$ 

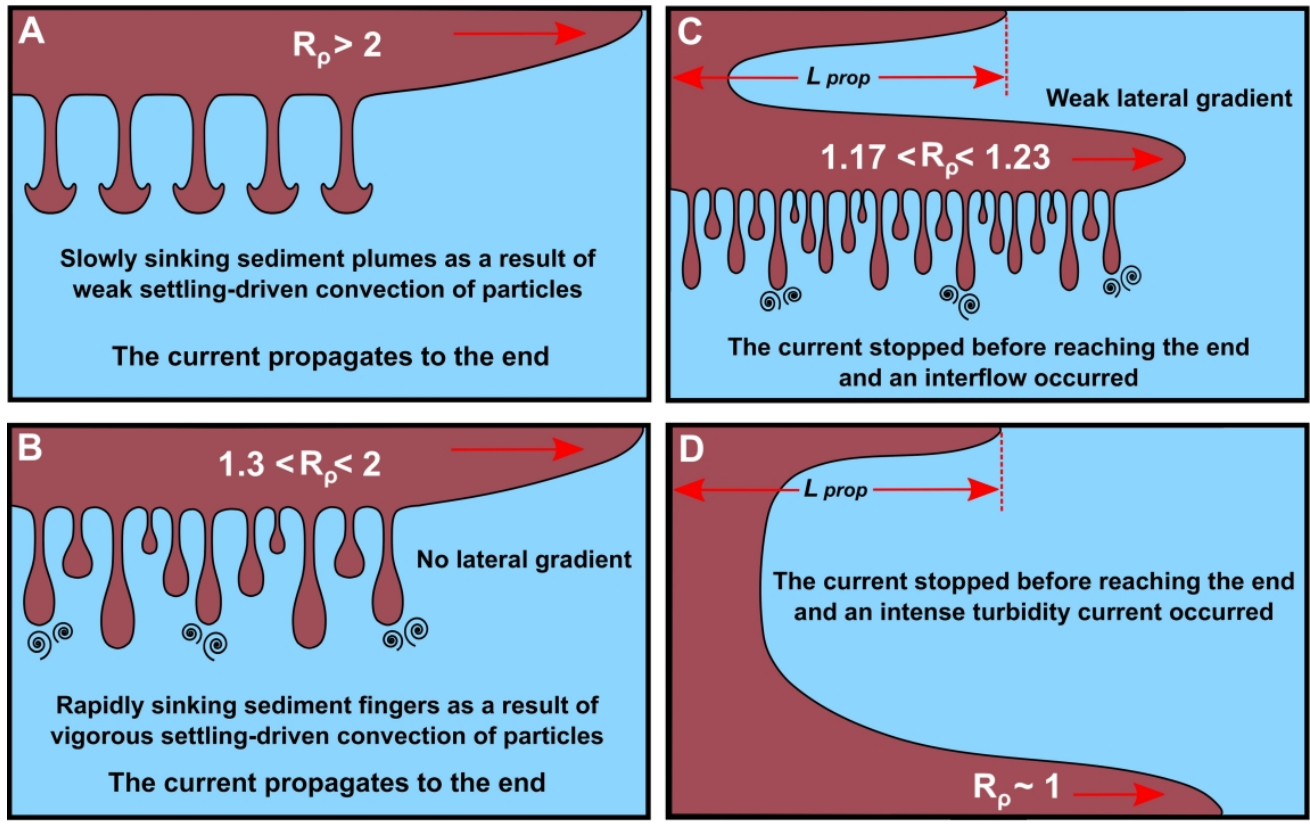

Fig. 9: Schematic figure summarizing the four main modes of convection that arose in the current experiments. (A) Slowly sinking sediment plumes for $R_{\rho}>2$, where weak settling-driven convection occurred and the current propagated to the end of the tank, (B) rapidly sinking sediment fingers for $1.3<$ $R_{\rho}<2$, where vigorous settling-driven convection occurred and the current propagated to the end of the tank, (C) occurrence of an interflow for $1.17<R_{\rho}<1.23$, where the surface plume stopped before reaching the end of the tank and (D) occurrence of an intense turbidity current for $R_{\rho} \sim 1$, where the surface plume did not reach the end of the tank. 


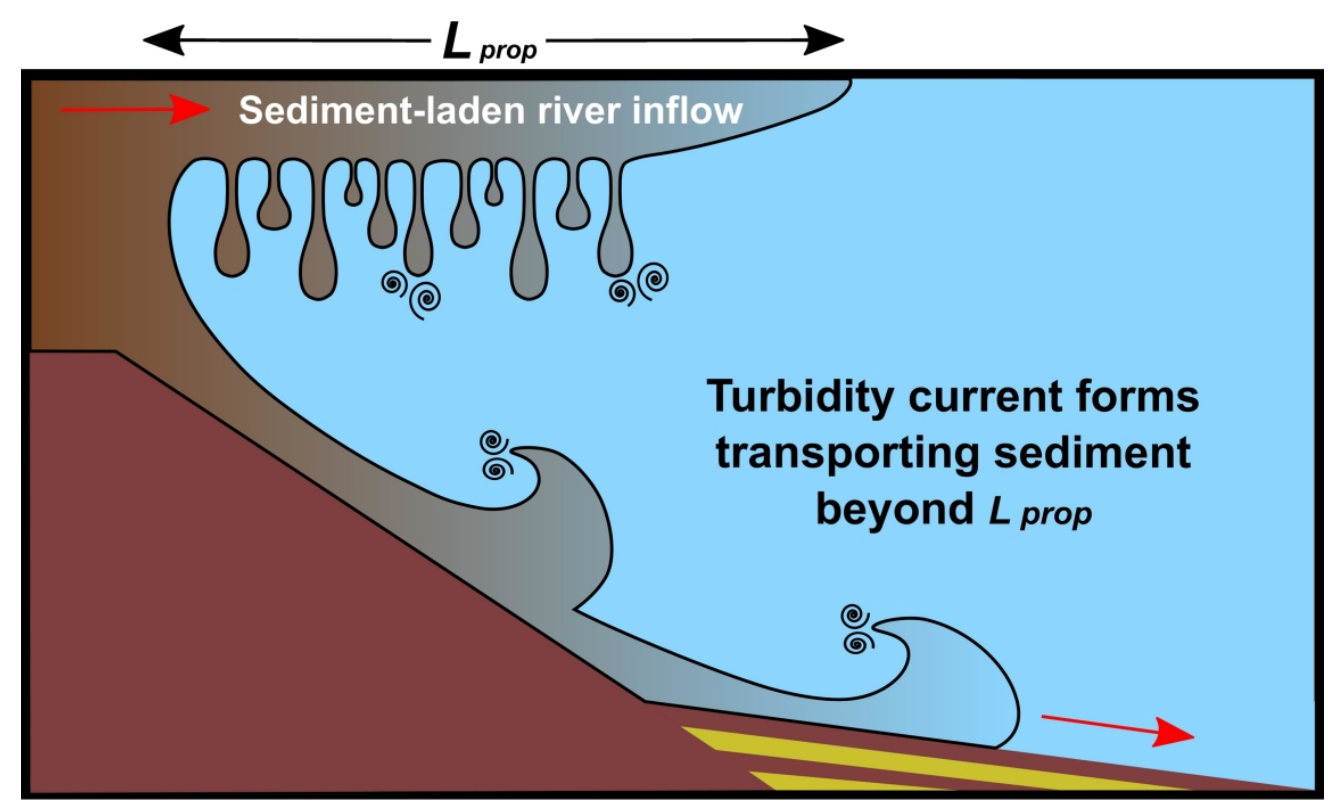

Fig. 10: The rapid loss of sediment from the surface gravity current can potentially form a turbidity current that can transport sediment particles and propagate distances much greater than $L_{p r o p}$. This is the more likely behavior when $R_{\rho}$ is close to 1 . The new experiments in this paper now suggest that Figure 1 is more relevant only for very large density ratios.

$285 \times 170 \mathrm{~mm}(300 \times 300$ DPI $)$ 

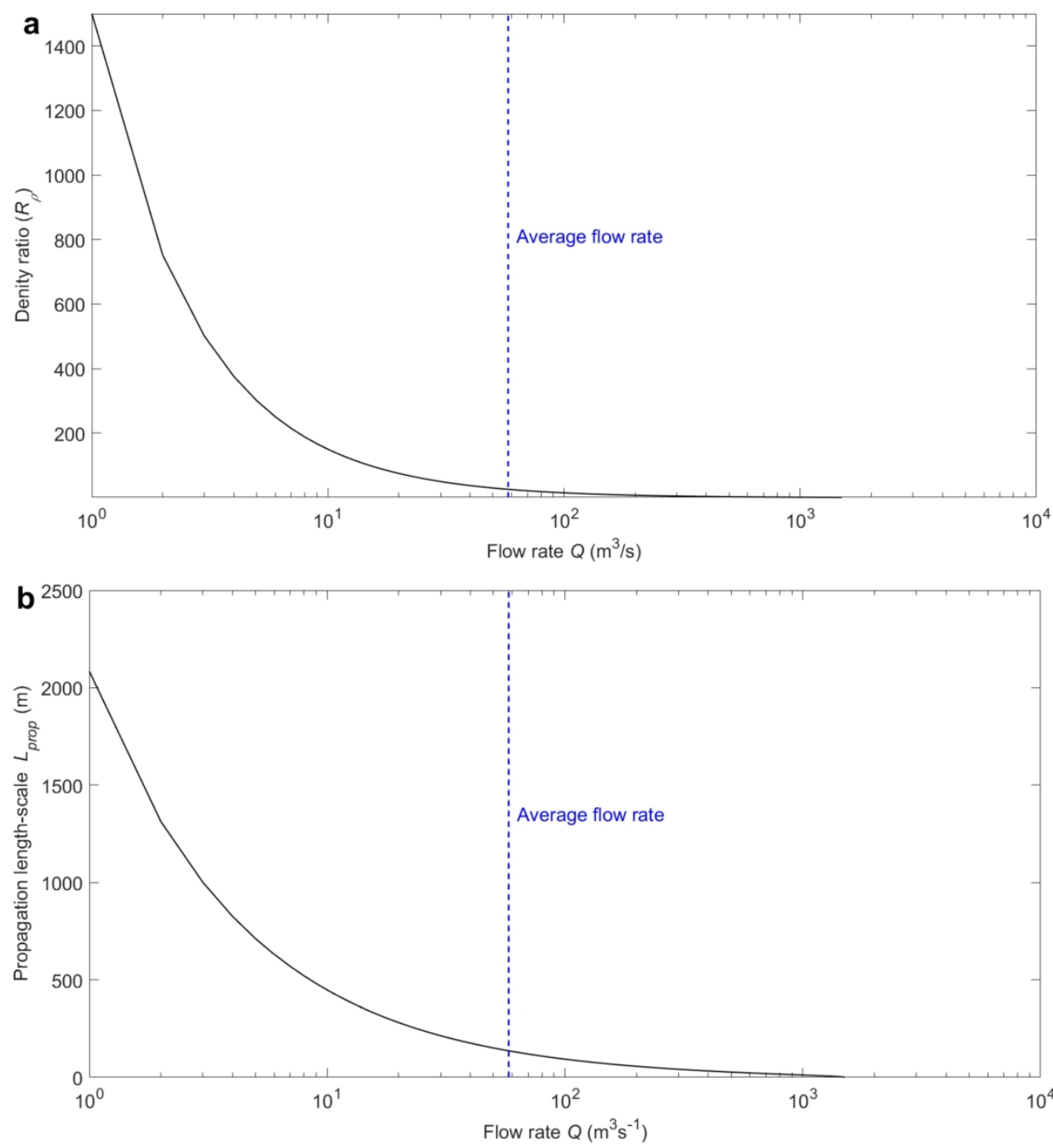

Fig. 11: The scaling for the propagation distance can be applied to sediment-laden rivers, if the sediment load is known. (A) The predicted density ratio $\left(R_{\rho}\right)$ as a function of the flow rate $(Q)$ for the Squamish River, using Equation (15) and data from Mulder \& Syvitski (1995). For high values of flow rate, the density ratio is less than one, implying the river can form a plunging flow. For lower flow rates, the density ratio can be much greater than one, as the density difference due to the added sediment is now less than the density difference between fresh and salty water. (B) The predicted propagation length-scale $\left(L_{p r o p}\right)$ is plotted as a function of flow rate values $(Q)$ using Equation (11). For values of flow rate greater than $1500 \mathrm{~m}^{3} \mathrm{~s}^{-1}, L_{p r o p}$ $=0$ as a plunging flow would form. For lower flow rate values the concentration of suspended sediment decreases, so that $L_{p r o p}$ increases with decreasing $Q$.

$201 \times 216 \mathrm{~mm}(300 \times 300 \mathrm{DPI})$ 